\title{
Comparing effectuation to discovery-driven planning, prescriptive entrepreneurship, business planning, lean startup, and design thinking
}

\author{
Yashar Mansoori • Martin Lackéus
}

Accepted: 7 August 2018 / Published online: 28 February 2019

(C) The Author(s) 2019

\begin{abstract}
There has been a growing interest among entrepreneurs and students in explicit guidance for entrepreneurial action. Both scholars and practitioners have responded to this demand by suggesting a variety of entrepreneurial methods. This has led, however, to a proliferation of relatively unrelated methods with varying degrees of rigor and relevance. In an attempt to organize and bring clarity to the range and diversity of entrepreneurial methods, this article compares effectuation with five other entrepreneurial methods along nine conceptual dimensions. Through the application of two conceptual frameworks, core underpinnings of each method are highlighted. In addition to revealing similarities and differences between the methods, the study identifies some key implications for theory, practice, policy, and education. The strengths of effectuation on a theoretical level could be used to develop other entrepreneurial methods. Conversely, the strengths of other entrepreneurial methods could be used to shore up the potential weaknesses of effectuation, such as a lack of behavioral tactics and limited applicability in later stages of venture development. Findings from this article can thus aid entrepreneurship scholars and practitioners to improve their
\end{abstract}

Y. Mansoori · M. Lackéus $(\bowtie)$

Technology Management and Economics, Chalmers University of Technology, Vera Sandbergs Allé 8b, 41296 Gothenburg, Sweden e-mail: martin.lackeus@chalmers.se

Y. Mansoori

e-mail: yashar.mansoori@chalmers.se prescriptions and can create new avenues for developing entrepreneurial methods.

Keywords Entrepreneurial methods $\cdot$ Prescriptive theories · Effectuation · Comparison · Rigor · And relevance

JEL classifications $\mathrm{L} 26 \cdot \mathrm{M} 13$

\section{Introduction}

Prescriptive methods have recently attracted considerable interest in the field of entrepreneurship (Jones and Penaluna 2013). Methods are principles of thought and action that guide the theoretical and practical aspects of human action (cf. Neck and Greene 2011; Mansoori 2017; Romme and Endenburg 2006). A main source of prescriptions for entrepreneurs is the widespread scholarly effort to empirically describe and categorize entrepreneurial processes (cf. Romme 2016) and then to transform the results into prescriptive methods (Denyer et al. 2008) for how entrepreneurs should reason and behave in order to create value. A prominent example of an entrepreneurial method is effectuation, presented as a set of heuristics any entrepreneur could use to develop a new venture in the face of uncertainty (Sarasvathy 2001). Another main source of prescriptions for entrepreneurs stems from expert entrepreneurs themselves, who have distilled their personal and idiosyncratic experiences into relatively coherent prescriptive advice. A widespread example is the lean startup methodology, 
prescribing that entrepreneurs formulate and test venture hypotheses through interacting with customers (Ries 2011).

Prescriptive methods of entrepreneurship have been criticized, however, for their lack of rigor and relevance. Practitioner-grounded entrepreneurial methods have met with criticism for lacking theoretical rigor (Wood 2000), which has led to undesirable consequences, such as entrepreneurs giving up prematurely (Heitmann 2014). Scholarly grounded entrepreneurial methods have been said to lack both practical relevance (Frank and Landström 2016) and theoretical rigor (Arend et al. 2015). One shortcoming of methods is a lack of trustworthiness due to the context-specific nature of entrepreneurship and thus the limited applicability of largely untested prescriptions. Another frequently cited shortcoming is a lack of practical usefulness due to limited concrete actionable advice (Wolf and Rosenberg 2012). An illustrative example is a recent debate concerning effectuation, which has been cast as an underdeveloped theory lacking practical managerial tools and with the potential to lead to dangerous practices among entrepreneurs (Arend et al. 2015). The concern has been that it could tempt entrepreneurs to ignore the risks of competition and to neglect the need for even the most rudimentary planning practices.

In an attempt to further the development of the field of entrepreneurial methods, this article compares effectuation in a highly detailed manner with five other entrepreneurial methods. Similarities, differences, strengths, weaknesses, overlaps, and gaps are explored along nine key conceptual dimensions. This process helps organize the field of entrepreneurial methods in a more comprehensible way for both scholars and practitioners. Increased clarity and visibility across the range of entrepreneurial methods may serve as a source of inspiration for work to improve existing entrepreneurial methods as well as to develop new ones. Thus, this article lays a foundation for proponents of entrepreneurial methods to use in future work. Proponents of practitioner-grounded entrepreneurial methods could increase the theoretical rigor of their prescriptions by drawing on scholarly grounded entrepreneurial methods. Similarly, proponents of scholarly grounded entrepreneurial methods could use this comparison to increase their practical relevance by drawing on practitioner-grounded entrepreneurial methods. Works that build on the comparison conducted here can serve as a bridge between different prescriptive endeavors in entrepreneurship that are developed in relative isolation.

In order to avoid bias toward any one particular entrepreneurial method, a conceptual framework is developed through an in-depth analysis of effectuation and five other purposefully selected entrepreneurial methods. These are discovery-driven planning (McGrath and MacMillan 1995), prescriptive entrepreneurship (Fiet 2008), business planning (Steinhoff 1971), the lean startup methodology (Ries 2011), and design thinking (Brown 2008). Choices of entrepreneurial methods were based on the following: citation analysis, appearance on entrepreneurship courses' syllabi (see footnote in Section 2.3), perceived alignment with the definition of entrepreneurial method, and informal inquiries with a number of experienced entrepreneurship researchers around frequency of use in their educational practices. Three entrepreneurial methods with scholarly origins were included alongside three methods introduced by practitioners. The conceptual framework consists of nine dimensions and is used as a means to elucidate similarities and differences. The discussion will then delve more deeply into the subject of effectuation, contrasting it to the five other entrepreneurial methods.

The article proceeds as follows. First, previous literature in relation to prescriptive work in entrepreneurship is presented. Then the framework of nine conceptual dimensions is developed in three steps and used for an in-depth comparison between effectuation and five other established entrepreneurial methods. A number of issues arising from this comparison are discussed, followed by an articulation of implications for theory, practice, policy, and education.

\section{Literature review}

\subsection{Descriptive and prescriptive theories of action}

Action theories can be divided into two different types: descriptive and prescriptive (Tsang 1997). Descriptive theories are often highly empirical and describe how individuals think and act in different situations. They frequently outline logical consequences, such as "under condition C, following action A leads to outcome O" (Parsons et al. 1965). By providing such propositions, they allow for predicting the outcome of specific actions when particular conditions are in place. Descriptive 
theories are judged by their empirical validity, that is, the extent to which they are consistent with the observed behavior (Bell et al. 1988; Tietz 1992).

Prescriptive theories help people decide what to do and how to think in a particular context (Cross and Sproull 2004). A key feature of prescriptive theories is that they are intended to influence and change the behavior of actual people (Bell et al. 1988; March and Smith 1995). Therefore, they often include propositions such as "in order to arrive at outcome $\mathrm{O}$ under condition $\mathrm{C}$, do action A," intended to improve the quality of human judgment and decision-making. Prescriptive theories are often appreciated for their pragmatic value, in that they help individuals to excel in practice (Bell et al. 1988; Tietz 1992). While descriptive theories come in the passive form of "if ... then" propositions, prescriptive theories come in the active form of "in order to ... do this" (Argyris and Schön 1974).

\subsection{Methods as prescriptive theories of action}

In everyday as well as scientific language, a number of terms and their synonyms have been used to discuss prescriptive theories of action. Some examples are heuristics (Baker and Nelson 2005; Sarasvathy 2001), guidelines (Sull 2004), principles (Ries 2011), approach and techniques (McGrath and MacMillan 1995), framework (Blank and Dorf 2012), practice (Dean and Bowen 1994), process and procedure (Ackoff 1981), model (Fiet 2007), and method (Brown 2008; Ries 2011; Sarasvathy and Venkataraman 2011). For the sake of clarity, the term "method" will be used from this point going forward to address prescriptive theories of action. The term "method" was also chosen because of its ubiquity in academic circles and the fact that it connotes the guiding of actions, giving it both theoretical and practical relevance, and allowing it to function as a unifying term. Although the term "method" is common both in everyday life and scientific discourse, the many different definitions of the term can create confusion and hamper effective communication, warranting the establishment of a clear definition (D'Abate et al. 2003).

Landa (1999, p. 346) conceptualizes method as "a structured system of instructions and/or actions for achieving some goal." March and Smith (1995) refer to methods as a set of steps necessary to carry out a task. Vincenti (1990) describes a method as a design apparatus that entails various ways of thinking, judging, and eventually doing. In line with this, Dimov (2016, p. 25) suggests that methods can be proposed "in the form of design propositions or principles on the basis of review and synthesis of prior research findings." Neck et al. (2014, p. 11) define method as "a way of thinking and acting built on a set of assumptions using a portfolio of practices to encourage creating." By synthesizing definitions for the purpose of this article, a method is defined here as a coherent set of related principles and guidelines of thought and action that help to structure the theoretical and practical aspects of arriving at a set goal (cf. Mansoori 2017). Based on this, an entrepreneurial method is further defined as a coherent set of related principles and guidelines of thought and action that help to structure the theoretical and practical aspects of entrepreneurship (cf. Neck and Greene 2011; Sarasvathy and Venkataraman 2011).

\subsection{Entrepreneurial methods}

Following the proposed definition of entrepreneurial method, several preexisting methods can be classified as such. While some of them are not labeled as methods in the existing literature, the definition used here would qualify them as entrepreneurial methods. This may be the first effort to include methods such as these under the broad heading of entrepreneurial methods, as defined in this article. Although there may be several ways to present the methods, the focus in this section is to provide a brief historical trajectory of their emergence, diffusion, and arrival at the current stage.

Business planning emerged as a prominent collection of principles and guidelines in the early 1960s and attained widespread acceptance in the 1970s (Ackoff 1981; Porter 1980). It was mainly used to structure the operations of existing firms and guide strategic decisions, but throughout the years, it also served as a useful tool to signal legitimacy. Therefore, entrepreneurs began using it as a communication tool to attract investment (Karlsson and Honig 2009). The prevailing bias of venture capitalists and other funding agencies at the time put business planning at the forefront of the agenda for aspiring entrepreneurs (Upton et al. 2001). Numerous "manual books" were published to demonstrate what business planning processes looked like and how aspiring entrepreneurs should go about conducting them. To complement the business planning approach and to adapt it to the conditions of high uncertainty assumed by entrepreneurs, scholars such as McGrath and MacMillan $(1995,2000)$ proposed a new set of 
guidelines for using planning strategies in entrepreneurship. These were grounded in a philosophy of incremental development rather than a grand, long-term (often five-year) plan that was formulated before any entrepreneurial activity was even initiated. In their book entitled The Entrepreneurial Mindset: Strategies for Continuously Creating Opportunity in an Age of Uncertainty, they championed experimenting with entrepreneurs' subjective beliefs and assumptions around doing business that had been taken for granted in business planning practices.

This opened up space for theories that emphasized "designing" new business activities rather than "planning" for them. In 2001, Saras Sarasvathy proposed five principles that served to guide the actions of expert entrepreneurs in creating successful businesses (2001). She postulated that these five principles could be conceived of as best practices and, therefore, could be learned by aspiring entrepreneurs (Sarasvathy and Venkataraman 2011). Additionally, Baker and Nelson (2005) appropriated the concept of bricolage from sociology and applied it to entrepreneurship, packaging it as a set of guiding principles that entrepreneurs could use when faced with resource scarcity. In the meantime, the notion of experimentation (Thomke 1998, 2003), implicitly touched upon as part of effectuation and bricolage, began to gain traction. Books and research articles that advocated similar experimental approaches to business development acquired a modicum of popularity (Fiet 2002; Pfeffer and Sutton 2006; Sull 2004). They concluded that a high degree of uncertainty can only be effectively and actively reduced through an experimental process that converts assumptions to facts. Furthermore, they argued for making decisions grounded in information gathered from carefully crafted experiments. Building on this idea, prescriptive entrepreneurship (Fiet 2008) offered a set of systematic theoretical guidelines for discovering opportunities amid the growing scholarly interest in the construct of opportunity. The guidelines projected a competing logic to the alertness perspective and offered new avenues for entrepreneurs to discover latent and/or create new opportunities in their surroundings.

The methods of scholarly origin outlined above did not seem to diffuse much outside academic circles (Arend et al. 2015; Frank and Landström 2016). It was, instead, often the practitioner-grounded counterparts whose ideas were to reach a wider audience (Abrahamson 1991). Design thinking as a set of managerial guidelines started to gain momentum around 2006
(Rauth 2015). Designers Tim Brown, Roger Martin, and David Kelly of Stanford d.school and IDEO (a global design company) began to advocate for the application of design thinking in business and entrepreneurial contexts (Martin 2009), even claiming that they could revolutionize management education (Dunne and Martin 2006). Large firms such as Procter \& Gamble adopted design thinking and incorporated many of its key ideas into their processes (Leavy 2010). Some startup communities followed suit and used design thinking to structure their business activities (Sonalkar et al. 2016). In 2011, Eric Ries extrapolated from his own startup experiences and formulated a method he labeled "the lean startup methodology" (Ries 2011). The ideas were not new (e.g., Murray and Tripsas 2004) but were repackaged to appeal to the software industry. This was the first successful attempt to appropriate ideas reminiscent of experimental approaches to the context of entrepreneurship by a practitioner. Before Ries, Steve Blank had proposed similar ideas (Blank 2007), but he did not enjoy the same level of popularity and recognition as Ries. The lean startup methodology began to spread rapidly through hotbeds of entrepreneurship, such as Silicon Valley, and quickly reached a global audience among entrepreneurs and entrepreneurship practitioners. Other practitioners joined the emerging movement and added nuances and texture to the proposed guidelines (Blank and Dorf 2012; Furr and Ahlstrom 2011; Maurya 2012). Blank (2013) claims that, at the current moment, the lean startup methodology is the most popular entrepreneurial method around, with a striking range of entrepreneurs, incubators, accelerators, and entrepreneurship programs whose agendas are based on its fundamental principles. While scholarly grounded entrepreneurial methods have indeed attracted some attention, practitioner-grounded entrepreneurial methods appear to have reached the broadest audience among entrepreneurs and entrepreneurship practitioners. ${ }^{1}$

\footnotetext{
${ }^{1}$ A witness to this claim is the presence of the lean startup methodology (Ries 2011), customer development (Blank and Dorf 2012), and design thinking (Brown 2009) books on Amazon's top 20 business books list, and the corresponding absence of books on more scholarly grounded entrepreneurial methods. Another witness to this claim is an online review the authors conducted of syllabi of the top ten entrepreneurship programs worldwide according to the Eduniversal master's program ranking website. Business planning was mentioned at seven of the ten programs, the lean startup methodology and its siblings business model generation and customer development were mentioned at six of them, and design thinking was mentioned as reading essentials at five of them. Of the scholarly grounded entrepreneurial methods, only effectuation was mentioned, and only at one of the programs.
} 
2.4 A three-tier framework for prescriptions of entrepreneurial methods

An organizing framework constituted of three levels was recently proposed by Mansoori (2015). The framework consists of the three levels of logic, model, and tactics (see Fig. 1). Logic touches on issues that need to be dealt with at a higher level of thought and cognition; model acts as an intermediate level bridging thought and action, facilitating the transfer of entrepreneurial knowledge from prescribers to those seeking advice; and tactics concern the tools and practical strategies at a lower level of action and interaction. Mansoori (2015, 2017) claims that this framework can be used for several purposes, such as guiding the design and development of effective entrepreneurial methods, improving the comprehensibility of advice given to entrepreneurs, and facilitating the comparisons of different entrepreneurial methods in more structured ways. The framework can act as a bridge between scholars and practitioners, validating that entrepreneurial methods have the potential to connect ideas and actions in pragmatic ways. Given that scholars have been lamenting the gap between theory and practice (Frank and Landström 2016; Rynes et al. 2001; Weick 2001; Banks et al. 2016; Van de Ven and Johnson 2006), this new role for entrepreneurial methods could gain prominence and attention (Mansoori 2017).

While the work of Mansoori (2015) is the first framework of its kind in the field of entrepreneurial methods, there have been similar frameworks in other fields. Among others, research areas such as firm strategy (Casadesus-Masanell and Ricart 2010), business research (Bryman and Bell 2007), management ideas (Rauth 2015), language teaching-learning (Anthony 1963; Richards and Rodgers 2014), and total quality management (Dean and Bowen 1994) have all benefited from conceptual frameworks that organize the abstract and concrete aspects of their theories. These examples demonstrate the versatility of these kinds of frameworks and suggest that a similar framework might be applied to entrepreneurial methods. As such, Mansoori's (2015) three-tiered framework, shown in Fig. 1, will be used in this article to compare six entrepreneurial methods, and a more detailed account of it will now follow.

The higher level of logic represents an overarching way of thinking that guides entrepreneurial action and acts as a reference point in regard to the theoretical foundations of methods (cf. McMullen and Shepherd
2006). The higher level deals with fundamental issues, imparting a clear logic to the entrepreneurial methods that helps entrepreneurs relate cognitively to the entrepreneurial process (cf. Baron 2004). It also frames the entrepreneurial method, acting as an orienting device, with the capacity to guide activities throughout the various stages of the entrepreneurial process. Therefore, the overarching logic sets the stage for entrepreneurial thinking and provides some general rules and principles.

The middle level of model gives entrepreneurs a way to conveniently visualize the entrepreneurial process and establish key terms that can be used in discussions between prescribers and entrepreneurs. This aspect of the model can facilitate endeavors through simple explanations that entrepreneurs can apply to their own unique venture activities, thus accelerating the intersubjective and normative diffusion of the entrepreneurial method (cf. Rogers 1983).

The lower level of tactics prescribes activities, exercises, and practices in line with the overarching logic and the summarizing model. They are often detailed and specify the context of use and the outcomes of action. Therefore, they are implementation-oriented, geared toward accomplishing immediate objectives and important tools for influencing practice (Romme 2003). Tactics tie the abstract nature of the logic to the tangible realm of entrepreneurial practice, which give rise to what can be considered outcome by outsiders.

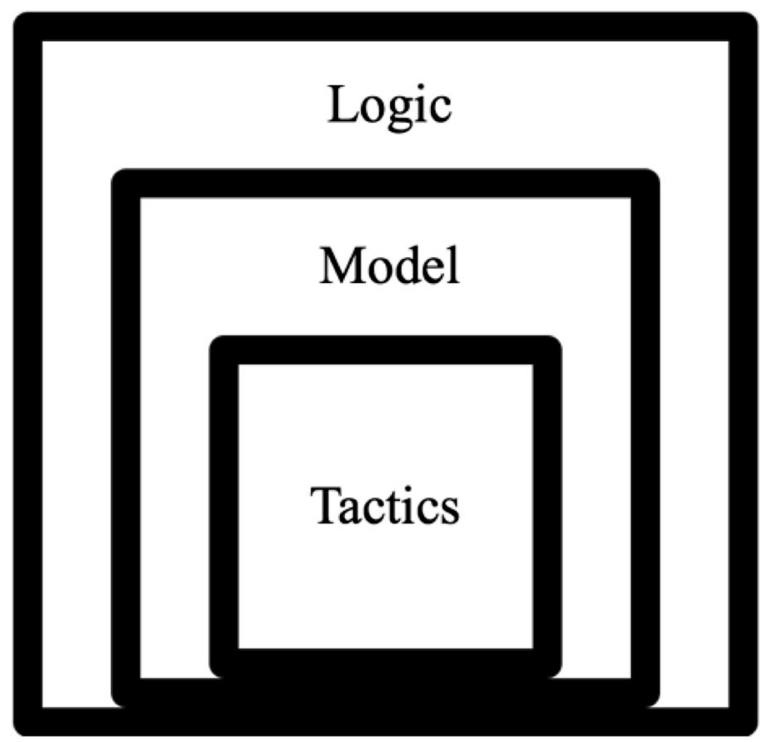

Fig. 1 Organizing three-tier framework comprised of three hierarchical levels of logic, model, and tactics 
Furthermore, they can be effectively documented by observational studies since they are closest to the sphere of concrete action.

\section{Developing a conceptual framework in three steps}

While the framework in Fig. 1 allows for a general three-tiered comparison across entrepreneurial methods, an in-depth comparison on a more fundamental level would necessitate a more fine-grained analysis. A framework has been developed here for this very purpose and involves a comparative analysis in three steps. In the first step, Mansoori's (2015) three-tiered framework allowed for the mapping of six entrepreneurial methods onto the three levels: logic, model, and tactics. In the second step, these levels were compared, resulting in the summary shown in Table 1 . In the third and final step, a more fine-grained framework consisting of nine conceptual dimensions applicable to the six entrepreneurial methods was developed. It was subsequently employed in another comparative analysis (see Section 4). These nine conceptual dimensions were inductively generated by reviewing existing literature on six entrepreneurial methods; information extracted from the literature was viewed as quasi-empirical data.

\subsection{Step 1: analyzing six entrepreneurial methods} across three levels

Effectuation emphasizes controlling the future rather than predicting it (Sarasvathy 2003). On a higher level of logic, effectuation "is rooted in the realization that human beings cause the future and, therefore, the future can be controlled and/or created through consensual human action" (Sarasvathy 2009, p. 27). Effectuation claims to address a logic of control (Sarasvathy 2001), promoting the idea that entrepreneurs' tasks are not limited to unearthing latent opportunities patiently waiting to be discovered. They also involve the actual creation of opportunities through a social process (Sarasvathy and Dew 2005a). Therefore, entrepreneurs begin with the universe of possible outcomes that can be created with the available means at their disposal (Sarasvathy 2001) and focus on continuous interactions with a committed network of stakeholders. On the middle level of model, five heuristics form the backbone of the effectual decision-making logic. Sarasvathy (2001) proposes these heuristics as follows: (1) starting the process by asking oneself who you are, what you know, and whom you know; (2) limiting risk by calculating how much one can afford to lose; (3) embracing the surprise factor and trying to use it as a leverage; (4) reducing uncertainty by obtaining commitment from early partners; and (5) focusing on activities within one's control rather than trying to predict the unknown future (Sarasvathy 2001). These five heuristics form a cycle to guide progress through the steps of the effectuation logic. On the lower level of tactics, effectuation offers a number of tools, such as means inventory, affordable loss assessment template, and effectual ask to uncover available resources. These can aid in the assessment of risks involved in venture creation activities. They can also guide the formation of the network of stakeholders and inform how to control the outcomes of a particular endeavor (Dew et al. 2018; Read et al. 2016).

Discovery-driven planning is an approach that combines business planning with learning through a series of steps that reveal key discoveries (McGrath and MacMillan 2000). On the higher level of logic, discovery-driven planning posits that uncertainty can be reduced by "systematically converting assumptions to knowledge and by redirecting its activities in the face of emerging understanding" (McGrath and MacMillan 2000 , p. 243). Proponents of discovery-driven planning maintain that, while conventional planning approaches are helpful in certain situations, they may be useless or even lead to disastrous outcomes in conditions of high uncertainty. Dysfunctional outcomes are largely due to reliance on untested assumptions. To manage the uncertainty, on the middle level of model, discovery-driven planning provides six areas of guidelines: (1) framing the desired business idea; (2) benchmarking the parameters that promise a successful outcome; (3) strategic translation of operations by specifying relevant organizational deliverables; (4) documenting, testing, and revisiting previously held or newly formed assumptions; (5) managing key milestones to reflect on actions taken and planning subsequent milestones; and (6) finding creative ways to run operations with a minimum amount of resources until major assumptions are tested (McGrath and MacMillan 2000). On the lower level of tactics, tools and techniques such as reverse income statement, targeted experiments, and assumptions checklists are offered.

Prescriptive entrepreneurship comprises a set of research-based guidelines outlining what entrepreneurs 


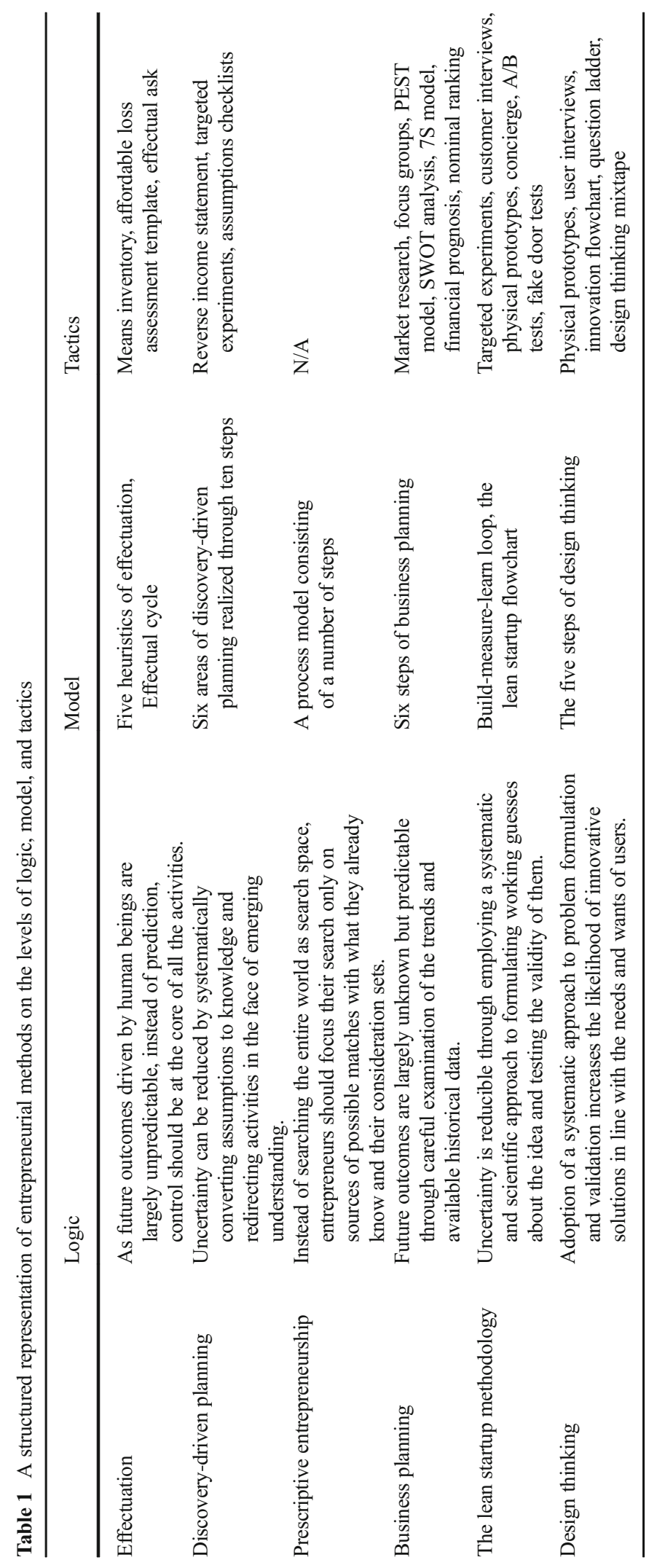


should do in order to improve their odds of success in wealth creation (Fiet 2008). On the higher level of logic, prescriptive entrepreneurship's rationale is that "entrepreneurial discovery depends on a fit between an entrepreneur's prior, specific knowledge, and a particular venture idea, which may be discovered systematically" (Fiet 2008, p. 190). Grounded in Bayesian learning, prescriptive entrepreneurship posits that entrepreneurs are only able to discover venture ideas that correspond to their "epistemic structure" (Fiet 2008, p. 26). Therefore, entrepreneurs should begin by systematically focusing on constrained prior experience, in other words on their acquired general and specific knowledge. In this context, "systematic" refers to how entrepreneurs "predetermine, based on their specific knowledge, how to search" (Fiet et al. 2013, p. 894) and "constrained" refers to the idea that entrepreneurs might derive more benefit from limiting searches to familiar information channels as opposed to the unbound scanning of the alertness perspective (cf. Kirzner 1997). On the middle level of model, Fiet (2008) highlighted five steps for a prescriptive model: (1) introspection about prior, specific, and general knowledge; (2) selecting information channels in accordance with own prior knowledge; (3) confining the search to the most preferred information channels; (4) searching for signals and quickly responding to them; and (5) interpreting feedback based on socio-cognitive factors. The goal of this process is to discover relevant signals in the form of informational cues about the environment (Fiet 2007). On the lower level of tactics, prescriptive entrepreneurship remains abstract. It offers theoretical notions such as information channels and consideration sets, but it does not provide ways for using them in practice, rendering implementation challenging.

Business planning is defined as "a process of ascertaining a series of potential courses to be taken by the firm, determining the firm's position as a result of each potential course, comparing and weighing this position for all actions, and, on the basis of the evaluation, selecting the course of action to be followed" (Steinhoff 1971, p. 3). On the higher level of logic, the business plan should offer solutions to "a set of dependent and independent functional problems" (Ackoff 1981, p. 52). The business plan is the formal statement outlining the process of business planning. It is constructed around several functions in the internal organization and several other external factors that influence the entrepreneurial process. Business plans deal with issues such as customers, market objectives, risks, financial plans, management team, and milestone schedules (Draman 1995; Delmar and Shane 2004). They also include strategies such as cost minimization, and performance and sales maximization (Utterback and Abernathy 1975), differentiation, cost leadership, and focus (Porter 1980; Delmar and Shane 2003). On the middle level of model, there are a number of steps commonly associated with a business planning process: defining the business, developing its mission, setting goals and objectives, crafting a strategy to achieve the objectives, identifying the required resources, establishing a resource acquisition and allocation plan, executing the strategy, evaluating performance, and initiating corrective adjustments (Draman 1995; Steinhoff 1971). On the lower level of tactics, approaches such as market research (Hong et al. 2013), focus groups, SWOT analysis, PEST model, 7S model, financial prognosis, and nominal ranking assist entrepreneurs in the process.

The lean startup methodology is "a set of practices for helping entrepreneurs increase their odds of building successful startups" (Ries 2011, p. 20). On the higher level of logic, the lean startup methodology is founded on "the realization that although human judgment may be faulty, we can improve our judgment by subjecting our theories to repeated testing" (Ries 2011, p. 150). Such repeated testing or purposeful experimentation is specifically designed to provide validated learning about a new product or service (Maurya 2012; Ries 2011). Evidence is gathered through close and constant interactions with current and potential customers and used to validate or invalidate key assumptions of the venture. On the middle level of model, the lean startup methodology provides the "build-measure-learn" diagram: (1) mapping a business idea onto testable business model assumptions (Osterwalder and Pigneur 2010) and building a "minimum viable product" (MVP) that allows for collecting feedback, (2) testing the product with customers and objectively analyzing the results of the completed tests to validate or invalidate key assumptions, and (3) learning from the results and designing the next rounds of experiments. Additionally, the proponents of the lean startup methodology rely on customer development (Blank and Dorf 2012) as a guiding tool, which entails four stages of customer discovery, customer validation, customer creation, and company creation. These processes are designed to reduce uncertainty through the accumulation of detailed and accurate information. On the lower level of tactics, the lean startup 
methodology relies on a set of tools that are appropriated from other domains, such as rapid prototyping (Brown 2008) and agile software development principles (Dybå and Dingsøyr 2008). Tactics such as customer interviews, targeted experiments, physical prototypes, concierge, fake door tests, and A/B tests all allow for quick feedback collection and advancement of the process.

Design thinking is "a discipline that uses the designer's sensibility and methods to match people's needs with what is technologically feasible and what a viable business strategy can convert into customer value and market opportunity" (Brown 2008, p. 86). On the higher level of logic, design thinking is "the application of integrative thinking to the task of resolving the conflict between reliability and validity, between exploitation and exploration, and between analytical and intuitive thinking" (Martin 2009, p. 171). Design thinking is grounded in an iterative, nonlinear, and humancentered practice based on user research. The process begins with defining the problem that users experience, understanding it in depth, creating a possible solution and testing it, and ends with reflecting on the results (Liedtka and Ogilvie 2011; Carlgren et al. 2016). It is through this process of creating, testing, and learning that entrepreneurs can better their initial venture ideas (Brown 2008). On the middle level of model, design thinking consists of five steps: (1) empathizing with the problem by understanding it from the perspective of users, (2) defining the problem in detail by making sense of the dispersed information, (3) brainstorming different ways the problem might be solved through generating a wide range of possible solutions and combining imaginative insights about these solutions, (4) prototyping a solution to highlight its strengths and weaknesses to identify new paths, and (5) testing the solution with users through soliciting feedback about prototypes to gain a better understanding. On the lower level of tactics, design thinking offers tools such as user interviews, physical prototypes, question ladders, innovation flowcharts, and design thinking mixtapes as aids to the process.

\subsection{Step 2: comparing six entrepreneurial methods across the levels of logic, model, and tactics}

For the level of logic, Table 1 illustrates several critical assumptions about the nature of the venture creation process, specified through theoretical and philosophical axioms. Examples include the notion of uncertainty
(McKelvie et al. 2011), the view of the future in relation to the level of skepticism of the predictability of outcomes (Tetlock and Gardner 2016), and the nature of the process as discovery or creation (Alvarez and Barney 2007). All the entrepreneurial methods that were reviewed explicitly or implicitly address the logic of their prescriptions. For example, business planning employs scenario building as a way to "predict" the future, while effectuation relies on heuristics for controlling present conditions while creating future ones. Knowledge and evidence are other notions central to the level of logic in almost all of the surveyed entrepreneurial methods. It is through the process of knowledge gathering by interacting with the external world that entrepreneurs engage in a process of learning (Cohen and Levinthal 1990) and eventually reduce the uncertainty they face.

For the level of model, Table 1 shows that a number of models prescribe procedural steps that represent the iterative nature of the entrepreneurial process. Such models can be conceived of as summarizing heuristics or algorithms. In some models - such as the lean startup methodology, effectuation, and design thinking - there are a clear order and feedback loops as part of their prescriptions. These methods all present explicit models with iterations for how to make progress toward the realization of entrepreneurial objectives. Business planning provides a clear sequence for necessary activities but is designed to be used at the start of the process or in a predefined cycle (i.e., the annual planning cycle). Nevertheless, it serves as an important model, enumerating specific steps and areas of focus. Several models refer to the involvement of external stakeholders. For instance, the lean startup methodology suggests that informed decisions can be achieved through frequent interactions with external stakeholders, such as customers, partners, suppliers, and investors (Ries 2011; Klein 2013). Similarly, design thinking outlines steps for collecting user feedback in order to improve the quality of ideas and to refine them in line with the feedback received.

For the lower level of tactics, Table 1 illustrates that many of the entrepreneurial methods provide tactics that are aligned with their overarching logics. For instance, the lean startup methodology includes tactics such as concierge, A/B tests, and making early MVPs. Similarly, design thinking offers prototyping, customer interviews, and mixtapes to help entrepreneurs navigate the five phases of design thinking. Table 1 shows that 
the scholarly grounded entrepreneurial methods provide markedly less advice on this level than the practitionergrounded counterparts, illustrating a difference in inclinations for giving detailed and explicit prescriptions.

\subsection{Step 3: developing a framework of nine conceptual dimensions of entrepreneurial methods}

The framework shown in Fig. 1, with its disaggregation into three levels, allows for a structured review of entrepreneurial methods, which enhances the clarity and visibility across methods. As a result, the authors were able to more effectively identify patterns. For instance, having the level of logic in mind primed the authors to spot ideas about aspects of the venture creation process that corresponded to that particular level, namely providing and discussing ideas involving the cognitive aspects of the venture creation process (e.g., uncertainty management). The development of the framework of nine conceptual dimensions occurred in three stages. In the first stage, independent reviews took place over a period of 6 years, generating two different doctoral dissertations in which several conceptual dimensions for entrepreneurial methods were formulated (Mansoori 2015, p. 23-5; Lackéus 2016, p. 61). In the second stage, the independently formulated conceptual dimensions were integrated in five full-day workshops, during which the authors exchanged ideas to unite the frameworks. Some of the conceptual dimensions were merged to represent more inclusive dimensions. For instance, "nature of change" and "locus of agency" were merged to form "redirection power." Other dimensions were discarded, as they did not span a sufficient number of entrepreneurial methods. An example of a discarded dimension was "reliance on historical data," an important aspect of planning.

The entire process reduced the total number of conceptual dimensions to nine. As these nine dimensions were generated inductively from the six established entrepreneurial methods, none of the methods served as a baseline. This aspect of the process allowed for a more objective, unbiased, and generic comparison. In the final stage, the preliminary framework and dimensions were scrutinized by editors and peer reviewers, triggering minor revisions and eventually leading to these nine final dimensions: uncertainty management, resource management, knowledge expansion, redirection power, continuous learning, iterative process, stakeholder interaction, team collaboration, and value creation (see Table 2).
On the level of logic, many of the reviewed methods advise that entrepreneurs cope with uncertainty (i.e., uncertainty management) by systematically drawing on what is already known and then determining what information needs to be gathered (i.e., knowledge expansion), effectively making use of available and necessary resources (i.e., resource management). Most methods emphasize the importance of letting the generated insights direct the forward momentum of the process in drastic ways if necessary (i.e., redirection power). In the lean startup methodology, a drastic turn triggered by insights is called a "pivot." On the level of model, several methods outline a cyclical model (i.e., iterative process) of learning from interactions (i.e., continuous learning) with external stakeholders (i.e., stakeholder interaction). Effectuation (Wiltbank et al. 2006, p. 992; Read et al. 2016, p. 195) and the lean startup methodology (Ries 2011, p. 81) both contain visualization of cyclical models. Design thinking suggests a more back-and-forth approach, also resulting in an iterative process (Rauth 2015, p. 20). On the level of tactics, some methods emphasize taking action through team-based efforts (i.e., team collaboration) to create value for external stakeholders (i.e., value creation). The lean startup method involves creating an MVP. Design thinking, on the other hand, hinges on the creation of a prototype, and in effectuation, a key objective is to secure the commitment of stakeholders. Next, the framework with its nine conceptual dimensions will be used to conduct a second round of comparisons of the six entrepreneurial methods.

\section{Findings}

To yield insight into the foundational similarities and differences of the six entrepreneurial methods, this section examines the conceptual underpinnings that form the bases of their prescriptions. The section aims to bring to light where the methods overlap as well as where they diverge and differ. Table 2 helps carve out similarities and differences that these methods exhibit. The findings section is organized according to the nine conceptual dimensions developed in Section 3.

\subsection{Uncertainty management}

The first conceptual dimension speaks to the way entrepreneurial methods conceptualize the inherent 


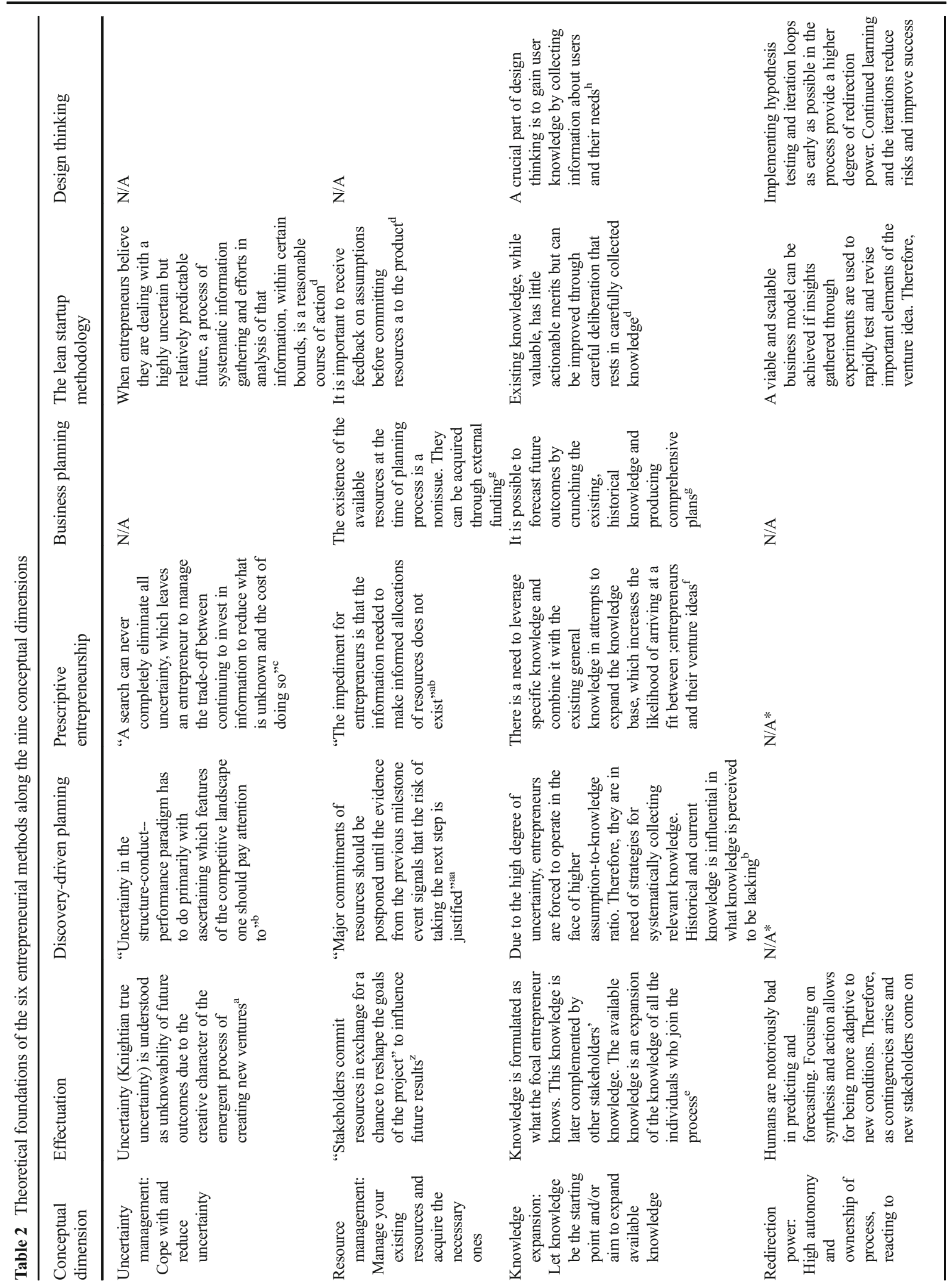




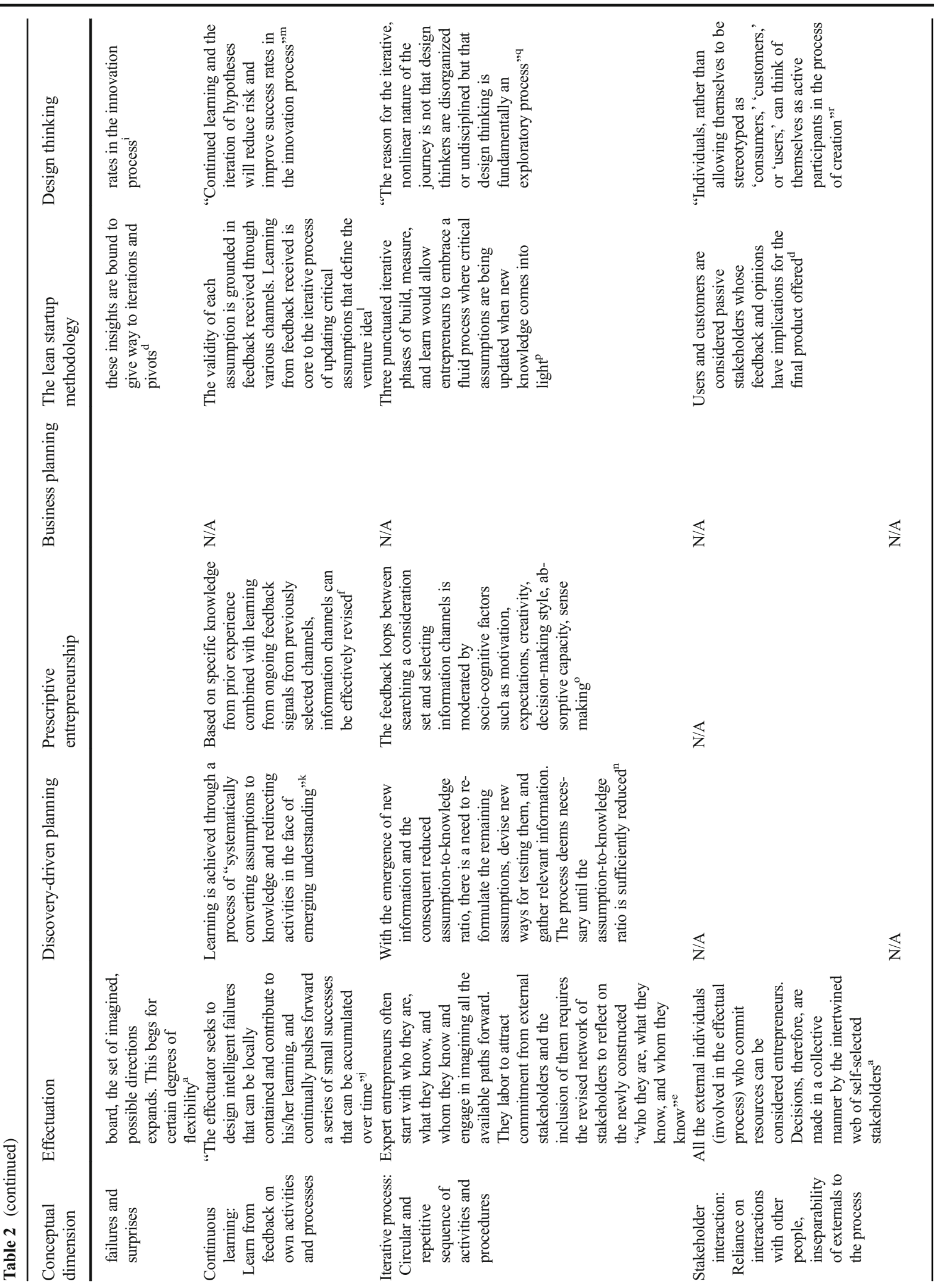




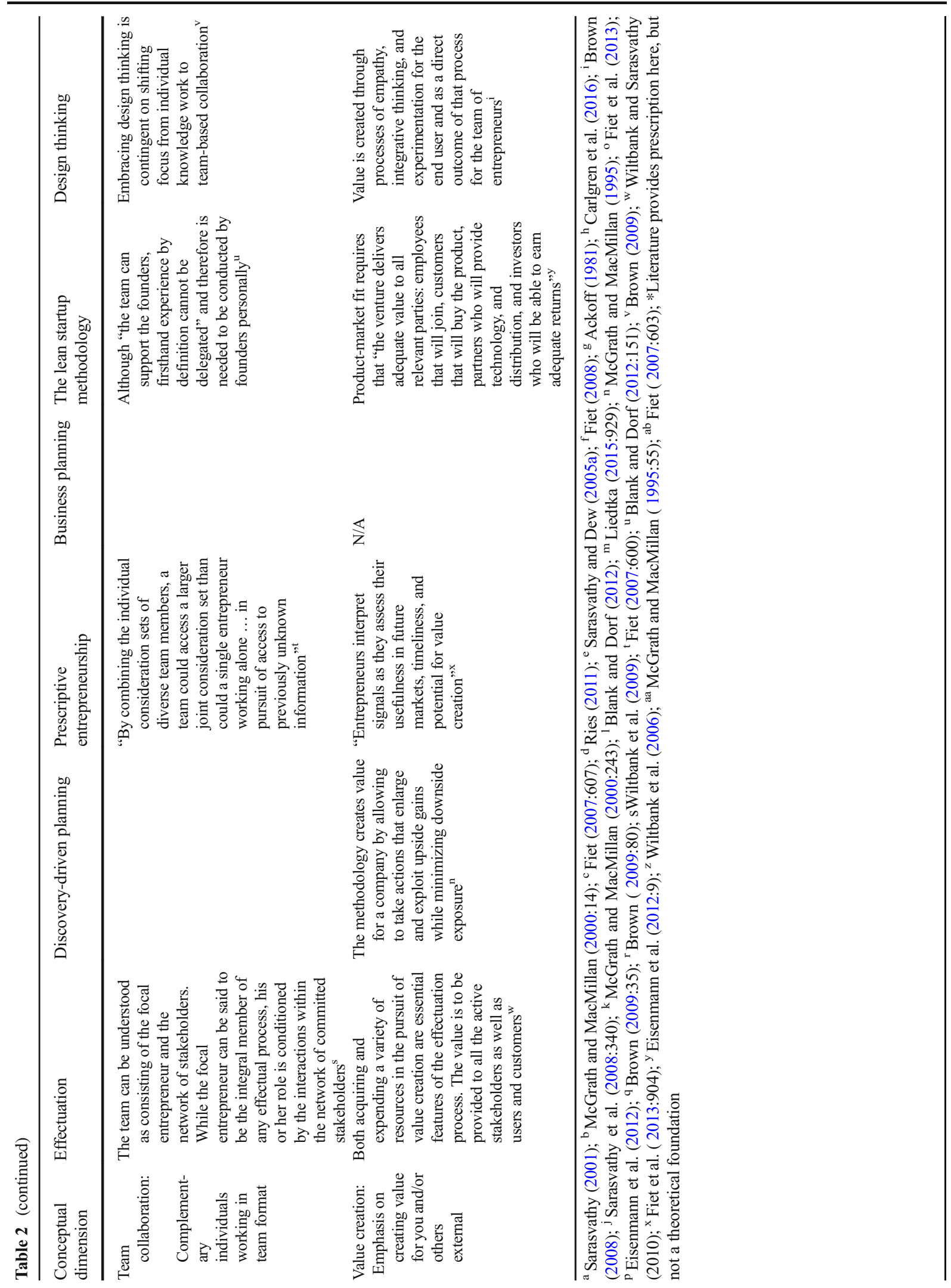


uncertainty present in current or future situations that entrepreneurs face as part of their venture creation efforts (cf. Gomory 1995; McKelvie et al. 2011). The view of future outcomes has important implications for how uncertainty should be managed (Sarasvathy and Dew 2005b). Apart from design thinking and business planning, the other methods explicitly or implicitly approach the notion of uncertainty, presenting it as one of the main reasons for the relevance of their prescriptions and proposing ways to manage or reduce it. The meaning of the term uncertainty, however, diverges along three main paths (cf. Packard et al. 2016). The first meaning is relevant to effectuation, in which uncertainty is ontological; that is, the future is unknowable in principle (Read et al. 2016; Knight 1921). Thus, the future is constructed by actors who are jointly creating it in unpredictable ways (Dew et al. 2008). The second meaning of uncertainty is seen in discovery-driven planning and prescriptive entrepreneurship, and frames uncertainty as epistemological; that is, the future is knowable through information gathering strategies (Fiet and Patel 2008). Here, uncertainty can be mitigated by entrepreneurs expanding their knowledge base. The third meaning for uncertainty reveals itself in the lean startup methodology, where a more implicit and colloquial meaning is found, incorporating concepts such as ambiguity and risk. It is most similar to epistemological uncertainty, the reduction of which hinges on the need to gather information (Murray and Tripsas 2004).

\subsection{Resource management}

The second conceptual dimension is concerned with how to use existing resources and acquire new ones through various strategies. Scarce resources play an important and integral role in any entrepreneurial process (Ozdemir et al. 2016; Baker and Nelson 2005), and entrepreneurial methods often provide recommendations for acquiring and managing resources. Depending on the overarching logic of the entrepreneurial methods, different standpoints are taken. Effectuation emphasizes the dynamic nature of the resources at hand by focusing attention on two issues: entrepreneurs should rely only on resources they are willing to lose, and self-selected stakeholders should be given the opportunity to (re)shape the future of the venture in exchange for committing resources (Dew et al. 2009). While discovery-driven planning grants more prominence to resources than business planning, they both offer guidance on how existing resources should be allocated (McGrath and MacMillan 2000; Shane and Delmar 2003). Yet, neither method suggests strategies for how to acquire these new resources. Within design thinking, there do not appear to be recommendations around resource management. Prescriptive entrepreneurship discusses resources primarily as information about the possible discovered opportunities and provides ways to acquire new ones (Fiet 2007). Finally, the lean startup methodology cautions that frugality must be exercised in initial tests of the venture idea, before the commitment of any major resources. Here, ideas around the scarcity of resources crystallize into the forewarning to fail early and fast (Khanna et al. 2016).

\subsection{Knowledge expansion}

The third conceptual dimension relates to activities aiming to expand the knowledge base beyond the level of personal and general knowledge an entrepreneur possesses at any given time in an entrepreneurial process. Knowledge plays an important role in entrepreneurship (Tang et al. 2012), and its importance is highlighted in most of the entrepreneurial methods. Except for business planning, in which the role of knowledge is more illustrative and representational, the other methods emphasize leveraging current personal and general knowledge in order to expand the repository of one's own knowledge. Effectuation and prescriptive entrepreneurship strongly emphasize personal knowledge as the starting point (Fiet 2008; Sarasvathy 2001), whereas other methods stress the importance of expanding the general knowledge base, regardless of its origin. A key observable difference between the methods has to do with ideas about how knowledge should be expanded (cf. Lundvall 1992). In effectuation, knowledge is expanded primarily when stakeholders in possession of new knowledge join the network, whereas in prescriptive entrepreneurship, the lean startup methodology, and design thinking, knowledge is expanded through carefully designed information gathering activities. These differences mirror the previously observed differences in conceptualizations of uncertainty management, suggesting a strong link between the acquisition of knowledge and the ability to manage uncertainty. 


\subsection{Redirection power}

The fourth conceptual dimension concerns the degree to which the methods recognize entrepreneurs' agency over the entrepreneurial process, especially in relation to new information, failures, and surprises (Garud and Karnøe 2003). Although all entrepreneurial methods except for business planning have a recursive understanding of the venture creation process, they permit varying degrees of process ownership (cf. Foss et al. 2007). Business planning has a linear understanding of its prescriptions, and although in reality there may be redirections in the process, the method does not, explicitly or implicitly, provide advice in this regard. While effectuation, design thinking, and the lean startup methodology explicitly embrace surprises and contingencies (Sarasvathy 2001; Johansson-Sköldberg et al. 2013), discovery-driven planning and prescriptive entrepreneurship guide entrepreneurs to avoid future surprises. It is important to note that, in principle, entrepreneurial methods are receptive to the idea of a change in direction. But a difference between the methods emerges with respect to the point at which these redirections happen. In effectuation, design thinking, and the lean startup methodology, redirections can happen any time new information is unearthed. In discovery-driven planning and prescriptive entrepreneurship, on the other hand, the decision to redirect is made at the end of a completed cycle. It is worth noting that, although discovery-driven planning and prescriptive entrepreneurship have incorporated redirectional ideas into their prescriptions (Fiet 2007; McGrath and MacMillan 1995), they fall short in providing explicit justifications for why these changes to direction in the face of emerging understanding are relevant and necessary.

\subsection{Continuous learning}

The fifth conceptual dimension refers to the role of feedback and how it provides learning opportunities for entrepreneurs during venture creation activities. Continuous learning from feedback plays an important role in shaping the trajectory of the entrepreneurial process (Minniti and Bygrave 2001). Feedback can be the outcome of a deliberate process of information gathering, as in the lean startup methodology, design thinking, and discovery-driven planning. It can also be the result of serendipity and happenstance, as in effectuation and prescriptive entrepreneurship (Harmeling and Sarasvathy 2013). In all entrepreneurial methods except for business planning, a high value is placed on continuous learning and the philosophical grounding of the venture creation process in newly learned insights. Feedback from the external environment is stressed as a source of continuous learning (cf. Kolb 1984). Effectuation deviates somewhat from the other methodologies by placing less focus on continuous learning as an inherent strategy and more as a by-product of following other recommendations. The lean startup methodology and, to some extent, design thinking are more explicit, using validated learning as a cornerstone of their main ideas. Such a continuous learning necessitates a need for revisiting and revising transient assumptions held by entrepreneurs in the face of newly acquired information (Ries 2011).

\subsection{Iterative process}

The sixth conceptual dimension relates to the temporal and evolving nature of entrepreneurial models. Entrepreneurship is a dynamic process that requires flexibility and constant adaptation (Bruyat and Julien 2001). All entrepreneurial methods, with the exception of business planning, describe models that allow entrepreneurs to react to new information and environmental conditions in dynamic and iterative ways. Regardless of the fact that these models could be understood as heuristics or algorithm-based, there is an explicit circular and repetitive aspect to them that suggests a continuous revising of assumptions and the reinvention of the process as new information is unearthed (cf. Argyris 1976). A major difference between the models proposed in these methods is what triggers the restarting of the process. In effectuation, the restart occurs when new stakeholders join the process, bringing with them a new set of means and expanding the set of possible futures to create (Sarasvathy 2003). In the other iterative models, the restart is triggered when new information is acquired through external sources as well as when the entrepreneur intuits a need to revise key assumptions. A subtle difference between methods is an emphasis on iteration. The lean startup methodology, design thinking, and effectuation are fundamentally grounded in iterative processes, whereas discovery-driven planning and prescriptive entrepreneurship include relatively minor feedback loops that may or may not result in iterative processes. 


\subsection{Stakeholder interaction}

The seventh conceptual dimension refers to the reliance on interactions with others. While it remains largely under-researched, intersubjectivity has had a central position in thinking about entrepreneurship (Sarasvathy and Venkataraman 2011). Entrepreneurs interact intensively with those who are directly involved in the process in various capacities as well as with more peripheral stakeholders who indirectly impact the direction of the venture creation process (Hart and Sharma 2004). Discovery-driven planning, prescriptive entrepreneurship, and business planning do not provide advice about stakeholder interaction. Instead, they focus on activities to be completed by the focal entrepreneur, that is, the entrepreneur who owns the initial idea and process and has the largest impact on the direction of the new venture (cf. Kotha and George 2012). In effectuation, the lean startup methodology and design thinking interactions with stakeholders comprise important sources of feedback and new information (cf. Lundvall 1992; Tunisini and Zanfei 1998). These interactions constitute a large proportion of key activities, especially in the early stages of the new venture development. In the lean startup methodology and design thinking, stakeholders are defined as users, consumers, and customers who provide valuable insights that can be incorporated into and contribute to the evolution of the venture idea. It is noteworthy that these entrepreneurial methods limit the involvement of users and customers to soliciting feedback; in other words, they recommend keeping them at arm's length. In contrast, effectuation regards stakeholders quite differently. Effectuation scholars define active stakeholders as any individuals who commit resources; these stakeholders are participating in the collective process of shaping the destiny of the new venture.

\subsection{Team collaboration}

The eighth conceptual dimension speaks to the role that individuals with complementary and diverse skill sets play as team members in an entrepreneurial process. Team-based efforts are increasingly emphasized in entrepreneurship research as a means to elicit and capitalize on a larger set of heterogeneous competencies (Klotz et al. 2014; Lechler 2001; Harper 2008). An important difference observed among the methods pertains to ideas about teams. In effectuation, the team boundaries are highly fluid and dynamic. Anyone who commits resources can be considered a team member and can play a role in the future of the venture. The group that forms is referred to as the "network of stakeholders," which is in many ways similar to what some of the other entrepreneurial methods label as a "team." Effectuating individuals are difficult to replace, as they have key roles in shaping the direction of the venture. These roles emanate from the idiosyncratic qualities these individuals possess (Sarasvathy and Dew 2005b). Design thinking, the lean startup methodology, and prescriptive entrepreneurship view teams differently. They regard them as a group of individuals with complementary skill sets who become responsible for specific aspects of the venture creation process based on their unique skills (Fiet 2008; Brown 2008; Blank and Dorf 2012). In these methods, most team members can be replaced by individuals who possess similar competencies. A key difference is that teams are more important in design thinking and less important in prescriptive entrepreneurship and the lean startup methodology. In discoverydriven planning and business planning, no explicit advice on teamwork or on necessity for collective efforts could be identified.

\subsection{Value creation}

The last conceptual dimension concerns the creation of value for entrepreneurs and others who may benefit from the outcome of the venture creation process. Creation of value, regardless of its recipients, is often the ultimate goal of the entrepreneurial process (Bruyat and Julien 2001; Korsgaard and Anderson 2011). All entrepreneurial methods except for business planning put value creation at the center. They make the venture creation process conditional on providing value to entrepreneurs and their teams, to active stakeholders, and/ or to users and customers. This does not imply that business planning activities and outcomes fail to create value for entrepreneurs. They indeed help create legitimacy and act as a marketing tool to attract investors (Brinckmann et al. 2010; Karlsson and Honig 2009). Rather, the activities as part of it are not designed primarily to provide explicit value to external stakeholders. While the prime beneficiaries of value in effectuation, discovery-driven planning, prescriptive entrepreneurship, and the lean startup methodology are entrepreneurs and their collaborators, design thinking emphasizes value creation for users, customers, and 


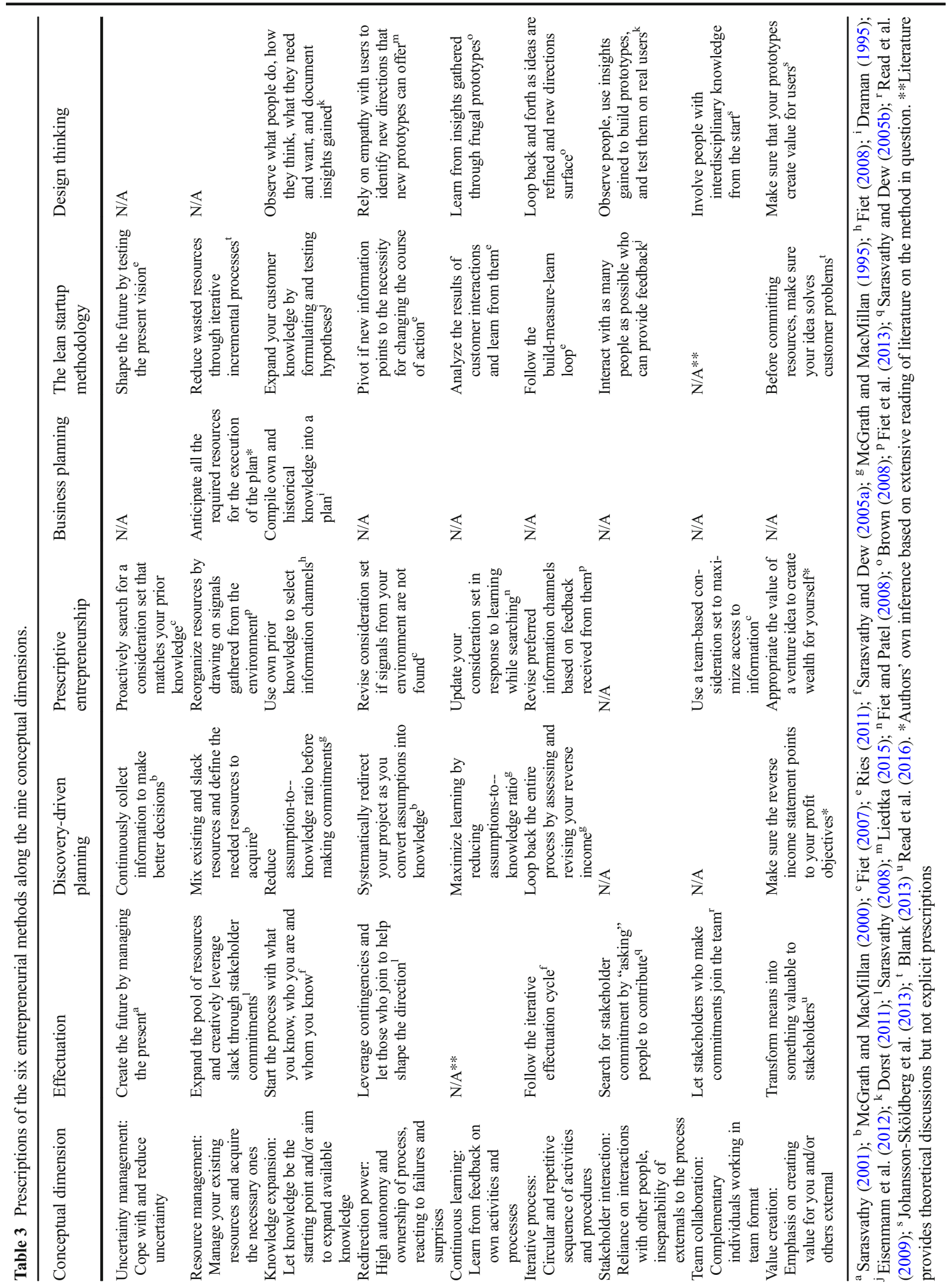


consumers (Martin 2009). Amid these subtle differences, Table 2 captures the role of value creation as an important factor for organizing new venture creation activities.

\section{Discussion}

Table 3 summarizes the findings from the previous section, attempting to clarify similarities, differences, strengths, weaknesses, overlaps, and gaps on a conceptual level across all of the surveyed entrepreneurial methods. This is the first effort of its kind to compare entrepreneurial methods along nine broad conceptual dimensions. Each cell in Table 3 contains typical prescriptive statements, which have been either clearly articulated in the methodologies or inferred by the authors of this article. Table 3 also reveals conceptual gaps in some of the methods, particularly in business planning, underscoring the need for improvements.

While some methods appear similar upon first glance, variations in the details are often relatively large. Whereas effectuation calls for entrepreneurs to manage uncertainty by taking action to create the future, in the lean startup methodology, entrepreneurs discover the future through testing carefully designed hypotheses. Effectuation further advises entrepreneurs to expand self-knowledge through introspection (Dew and Sarasvathy 2010), in contrast to design thinking, in which entrepreneurs derive knowledge through observational studies of other people. While effectuation defines a redirection situation as an opportunity to "leverage contingencies," the lean startup methodology frames redirection as an unfortunate but necessary "pivot." In the lean startup methodology and in effectuation, continuous learning comes primarily from interactions with customers and stakeholders, respectively, whereas in design thinking, continuous learning comes primarily from testing prototypes on users. Effectuation describes the iterative process as revolving around stakeholder commitments, whereas iterations in the lean startup methodology and design thinking have to do with building frugal prototypes. Effectuation is largely focused on value creation for oneself and the team, whereas the lean startup methodology and design thinking are focused on value creation for others (i.e., for customers and users).

Table 3 also illustrates some key differences between entrepreneurial methods along the nine conceptual dimensions. Stakeholder interaction is a key theme in effectuation and in the lean startup methodology. It is present in design thinking alongside the imperative of observing stakeholders. It is, however, largely absent in discovery-driven planning, prescriptive entrepreneurship, and business planning. Team collaboration is a key theme only in design thinking. It is partly or completely absent in the other entrepreneurial methods.

\subsection{Analytical visual comparison across methods and dimensions}

In order to more powerfully illustrate the conceptual similarities and differences in Tables 2 and 3, the authors created a figure to show the weights assigned to each of the nine conceptual dimensions according to the extent to which they are emphasized by a given entrepreneurial method. A set of qualifying criteria was developed to assign a grade ${ }^{2}$ for each dimension on a scale of 0 to 3 . If a dimension was deemed fundamental to the theory or prescriptions of a given method, then it was considered a backbone dimension and was given a grade of " 3 " for that particular method. If an entrepreneurial method directly referred to a dimension in discussions or prescriptions, that dimension was given a grade of " 2 " for that particular method. If a method made indirect or implicit reference to a dimension by touching upon similar or related concepts, a grade of " 1 " was given to that dimension for that particular method. And lastly, if an entrepreneurial method did not explicitly or implicitly address any aspects of a dimension, and it could be safely assumed that this dimension did not inform any relevant aspect of that particular method, a grade of " 0 " was given to that dimension. This quantitative exercise resulted in Fig. 2, which shows how the entrepreneurial methods compare to one another and to effectuation.

To illustrate the grading system, the process of grading uncertainty management is detailed here. Uncertainty serves as an ideological backbone in

\footnotetext{
$\overline{2}$ The inter-rater agreement between the two authors who independently conducted grading was relatively high, with 41 of the 54 grades being the same. Consensus was achieved in the remaining dimensions through extensive discussions among the authors and a detailed review of literature. The 13 grades requiring such discussions and reviewing were distributed as follows: three each on team collaboration and value creation; two each on resource management, continuous learning, and iterative process; and one on knowledge expansion. All grades on uncertainty management, redirection power, and stakeholder interaction were in agreement between the two authors. The entrepreneurial methods involved the most in such discussions were those that were given a low grade, since absence of a dimension proved to be more difficult to substantiate than presence.
} 
effectuation, in the sense that its five action principles are based on the assumption that entrepreneurial environments and associated activities are clouded with uncertainty (graded 3). Prescriptions for discoverydriven planning and prescriptive entrepreneurship are framed as suitable for uncertain entrepreneurial environments, but the actions were not designed specifically as a means to reduce uncertainty (graded 2). In the lean startup methodology, ambiguous and risky entrepreneurial environments are equated with uncertainty (graded 1). And lastly, design thinking and business planning are not positioned as responses to uncertainty and, therefore, they do not incorporate the notion of uncertainty into their prescriptions (graded 0 ).

While the grading exercise is subjective, the resulting figures illustrate patterns of potential relevance to the comparison. A similarity across most of the entrepreneurial methods is an emphasis on knowledge expansion, value creation, and iterative process, as well as a lack of emphasis on team collaboration. Given the methods were developed largely in isolation from one another, these similarities are somewhat unexpected. Some differences are also visible. Three of the entrepreneurial methods address the nine dimensions more comprehensively than the others: effectuation, the lean startup methodology, and design thinking. Moreover, redirection power and stakeholder interaction are important differentiators between them and the others. Business planning is largely mute on many of the nine dimensions.

Although some of the entrepreneurial methods incorporate most of the nine dimensions, they can nevertheless benefit from further elaboration in order to make them more comprehensible. For instance, the fact that effectuation is graded highly on stakeholder interaction does not necessarily mean that practical pointers are given for how individual entrepreneurs can form and leverage such interactions. In a similar fashion, the fact that the lean startup methodology is graded highly on continuous learning does not necessarily mean that the prescribed learning mechanisms are grounded in a theoretical understanding of continuous learning. In sum, the fact that an entrepreneurial method emphasizes a particular dimension does not make the emphasis actionable or rigorous.

In an attempt to deepen the surface-level observations for gaps, similarities, and differences shown in Table 3 and Fig. 2, two key themes will now be explored. The first describes two approaches to bridge the rigor-relevance gap in entrepreneurship. The second highlights three different venture phases, with implications for which methods are appropriate to follow during each phase.

\subsection{Bridging the rigor-relevance gap: two new ways}

A key difference between the entrepreneurial methods compared here is their origins: some are scholarly grounded and others are practitioner-grounded. This was a purposeful sampling strategy, and the comparison conducted here sheds a new light on this key difference on a deeper level. Table 1 revealed that effectuation, discovery-driven planning, and prescriptive entrepreneurship are lacking on the level of tactics, especially when compared to practitioner-grounded entrepreneurial methods that offer rather large toolkits for managing different aspects of the venture creation process. Previous research indicates that, in order to trigger actions, detailed instructions and prescriptions for behavior must be given (Fishbein and Ajzen 2010). If behavioral tactics are what make entrepreneurial methods actionable and in turn relevant to practitioners (Romme 2003), Table 1 can explain why practitionergrounded entrepreneurial methods are so widespread, as evidenced by Blank (2013) and Christiansen (2009). This also lends credence to previous claims that scholarly grounded methods are difficult for practitioners to understand (Romme 2016). In the same vein, Fisher (2012, p. 1044) notes that it is "really difficult for a wide audience to understand and interpret what is meant by effectuation." This comparison has illuminated, in a novel way, reasons why many scholarly grounded entrepreneurial methods are perceived by many as lacking practical relevance.

While Table 1 shows that all the entrepreneurial methods exhibit an overarching logic of some kind, the more fine-grained analysis in Table 2 reveals a number of shortcomings for practitioner-grounded entrepreneurial methods in terms of theoretical basis. Neither business planning nor design thinking provides articulated underpinnings of uncertainty management. Moreover, while the lean startup methodology discusses uncertainty to some extent, it does not engage in an ontologically or epistemologically sound discussion around what constitutes uncertainty, beyond referring to the need to eliminate it from entrepreneurial processes. Given that uncertainty is a fundamental characteristic underlying entrepreneurship (McMullen and Shepherd 


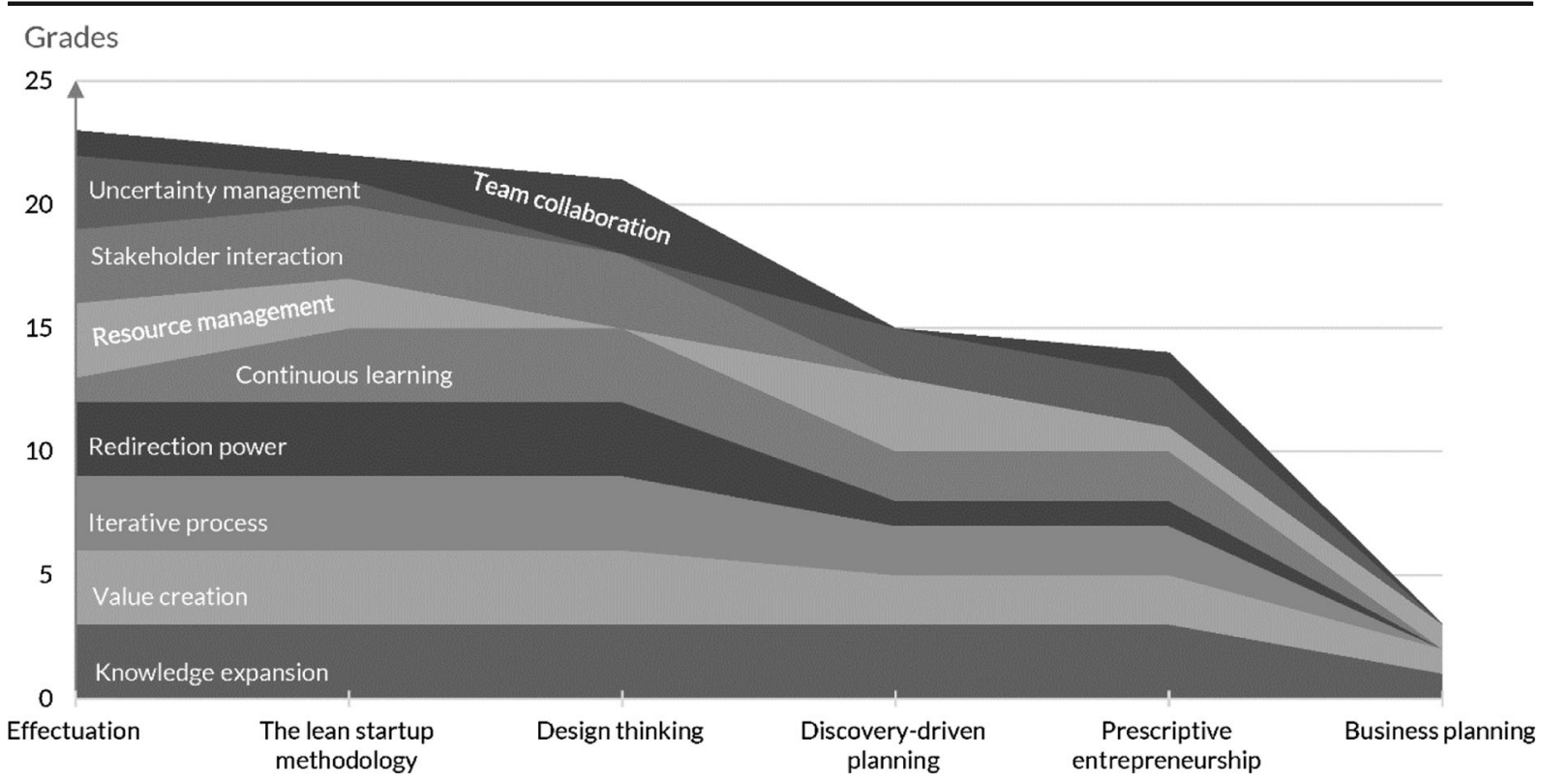

Fig. 2 Analytical comparison of six entrepreneurial methods across nine conceptual dimensions

2006), its absence or weak presence in practitionergrounded entrepreneurial methods may indicate a lack of rigor. These key differences are illustrated through a polar chart in Fig. 3, which shows an evaluation of the six entrepreneurial methods in terms of core, explicit, implicit, or no focus in discussions on uncertainty management.

This article provides a more fine-grained analysis of key characteristics of the rigor-relevance gap in relation to the six entrepreneurial methods. None of the surveyed methods are currently capable of fully bridging the rigor-relevance gap. In order to successfully do this, scholarly grounded methods need to be stronger on the level of tactics. Practitioner-grounded entrepreneurial methods, on the other hand, could benefit from improvements in the areas of ontology and epistemology in general and on their view of uncertainty management in particular.

\subsection{Importance of the venture phase for methodological} fit

Depending on which phase an entrepreneurial venture is in, redirection power in Table 2 seems to covary. In the early phase of a venture, redirection power, continuous learning, and relentless expansion of the knowledge base are to be expected. An example of an entrepreneurial method that corresponds to the early phase is effectuation. In this early phase, whoever joins the venture will be a potential "stakeholder," is allowed to reorient the venture, and will determine the path forward (cf. Sarasvathy 2001). Formal roles do not matter much since everyone is a stakeholder cocreating the journey, and any decision is the result of a joint process involving multiple negotiations and interactions among the stakeholders on board (Sarasvathy et al. 2005). In fact, one could argue that effectuation shies away from the notion of a core venture team and instead takes a more expansive view of a network of stakeholders, who eventually coalesce into a founding team (Wiltbank et al. 2006). This is similar to the notion of a nonteleological endeavor, in which arrival at an emerging goal is the outcome of the process itself (Dew et al. 2009).

In a later phase of the venture, there is a need for more structure (Clarysse and Moray 2004). Two prime examples are design thinking and the lean startup methodology. Here, redirection power, continuous learning, and knowledge expansion are more structured and organized through the process of hypothesis testing. Goals and visions are articulated by a small team known as "founders" (Blank and Dorf 2012) or "team members" (Brown 2009). The interactions are more formal and transactional than in effectuation, distinguishing those driving the process from their "customers" (Blank and Dorf 2012; Ries 2011) or "users" (Brown 2009). Here, redirection power is still quite high, but it is exploited at specific points in time. It is also referred to as "pivot" (Ries 2011) or "iteration” (Brown 2009; Liedtka 2015). 


\section{Uncertainty management}

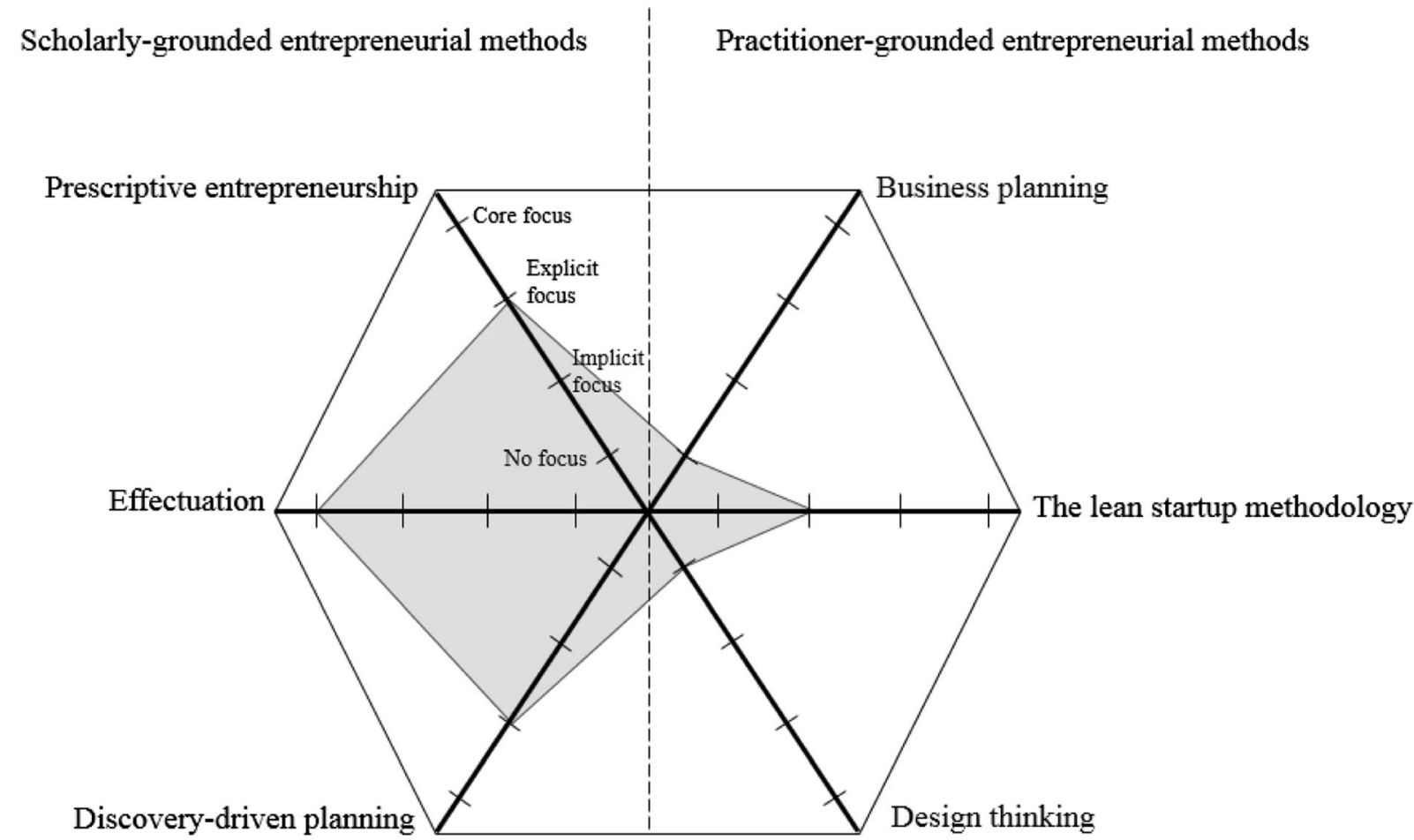

Fig. 3 Polar chart showing how focus on uncertainty management sets apart scholarly grounded entrepreneurial methods from practitionergrounded entrepreneurial methods

It reflects a higher degree of complexity and relies on clear roles and division of labor. The roles of the focal entrepreneur (Ries 2011) or the founding team (Brown 2009) are more prominent in these methods and the losses are less affordable due to more time and resources having been invested into the process of a later phase venture.

In mature ventures, redirection is not an affordable or desirable option except in very specific situations. An example of an entrepreneurial method appropriate here is business planning. This method exhibits little to no emphasis on redirection, continuous learning, or continuous knowledge expansion (see Table 2). Instead, it translates what is already known into plans before starting the journey and at predefined times throughout the journey. Business planning is focused on the execution of a goal defined at the outset, and all the activities are designed to further progress toward that goal (Shane and Delmar 2003; Karlsson and Honig 2009). An emphasis on necessity to plan carefully and avoid redirection whenever possible could be due to an implicit assumption that losses in mature ventures can be costly, as exemplified by later stage venture financing. Venture capitalists often request to review business plans before investing large amounts of money into a venture (Brinckmann et al. 2010).

The key differences that this venture phase observation makes explicit are illustrated in a polar chart in Fig. 4. This chart shows an evaluation of the six entrepreneurial methods in terms of a core, explicit, implicit, or no focus on redirection, based on Table 2 and Fig. 2. A key implication here is that the choice of entrepreneurial method is highly contingent upon the phase of the venture. Existing venture phase models articulated in extant literature could then perhaps be applied when deciding which entrepreneurial method is appropriate to use (e.g., Clarysse and Moray 2004; Hanks et al. 1994; Levie and Lichtenstein 2010). This has also been tentatively proposed recently (Reymen et al. 2015), building on a four-phase model consisting of idea phase, prestartup phase, startup phase, and post startup phase (Clarysse and Moray 2004). In this case, effectuation could then be positioned as useful primarily in the idea and pre-startup phases, design thinking and the lean 
startup methodology could be useful primarily in the pre-startup and startup phases, and discovery-driven planning and business planning could be useful primarily in the startup and post startup phases. This, however, must be viewed as a tentative proposition. No empirical research has yet been conducted on covariance between venture age, size, and growth rate, on the one hand, and multiple entrepreneurial methods used successfully, on the other hand. Venture phase models can also be misleading, resting on a false assumption that entrepreneurship is a linear and predetermined journey of growth (Levie and Lichtenstein 2010). Further, some entrepreneurial methods are opposing the claim implicit in phase models that entrepreneurial processes are linear (e.g., Blank and Dorf 2012: 32).

Despite the challenges in aligning entrepreneurial methods to existing venture phase models, the methods do seem to be complementary over time. When the stakes are low in a new venture, the applicable method might be effectuation, followed by a move to applying the lean startup methodology when the stakes are slightly higher. Then the time arrives for a venture ramp-up, for example, when bringing in large amounts of venture capital. At this stage, few investors would be willing to commit resources unless they were shown a detailed plan or proposal of some kind. Furthermore, having no explicitly stated goals necessitates constant change (i.e., effectuation viewed as a nonteleological endeavor), having fluid goals facilitates change (i.e., the lean startup methodology and design thinking), and having fixed goals leads to inflexibility in the face of change (i.e., business planning, discovery-driven planning, and prescriptive entrepreneurship).

To avoid premature assignment of entrepreneurial methods to certain venture phases, a venture phase agnostic metaphor of boating is proposed here to inspire future research. The size of the boat represents the phase of an entrepreneurial venture. Applying effectuation could then be viewed as traveling in a rowboat, where whoever boards the rowboat is allowed to row and thus reorient its direction somewhat. Any loss in speed or even of the boat itself is affordable, since the pace is slow and the boat is small. Space is limited, so each passenger needs to bring something of value on the journey. Applying the lean startup methodology could be viewed as traveling in a sailboat, where a redirection is analogous to upwind sailors tacking into the wind in carefully planned maneuvers. The more formal roles of a founder and a team are analogous to a captain and a sailboat crew, respectively, being a necessity on a more expensive and complex boat traveling in more dangerous waters. Applying business planning could be viewed as traveling in a large ferry toward a carefully planned destination, and where a loss of the boat is very costly.

\section{Implications}

\subsection{Implications for theory}

A key theoretical implication of this study is that scholars can use the key strengths of some entrepreneurial methods to improve aspects of other entrepreneurial methods that require theoretical and practical development. In particular, insights from this enquiry enable scholars to take advantage of the theoretical strengths that effectuation is grounded in and the strengths around actionable, tactical prescription that the lean startup methodology and design thinking provide. Our study also shows weaknesses among the six methods, especially in the areas of team collaboration and contextual sensitivity. For example, it might not make much sense to give effectuationbased advice when potential losses are far from affordable, or when roles and responsibilities are already established and when continuous redirection of strategic choices is a less viable strategy.

To advance beyond the current state of entrepreneurial methods, researchers need to recognize entrepreneurial methods as a legitimate field of scholarly inquiry. One way could be to adopt an integrated approach, combining different methods into more comprehensive meta-methods that are both "theoretically-driven and empirically-tested" (Fiet 2008, p. 11) in a broad variety of contexts and situations. Such work could be guided by the three-tiered framework and the nine conceptual dimensions put forth in this article and could draw from and relate to extant literature, such as venture success factors (Hong et al. 2013; Marmer et al. 2011) and innovation and startup ecosystems (Gauthier et al. 2017), among others. An integrated approach could also further the development of a prescription-based and pragmatic view of the entrepreneurial process. It is argued in this article that a combined view may be the most accurate and effective one. Perhaps entrepreneurship is when individuals manage uncertainty by expanding their knowledge and resource base through 


\section{Redirection power}

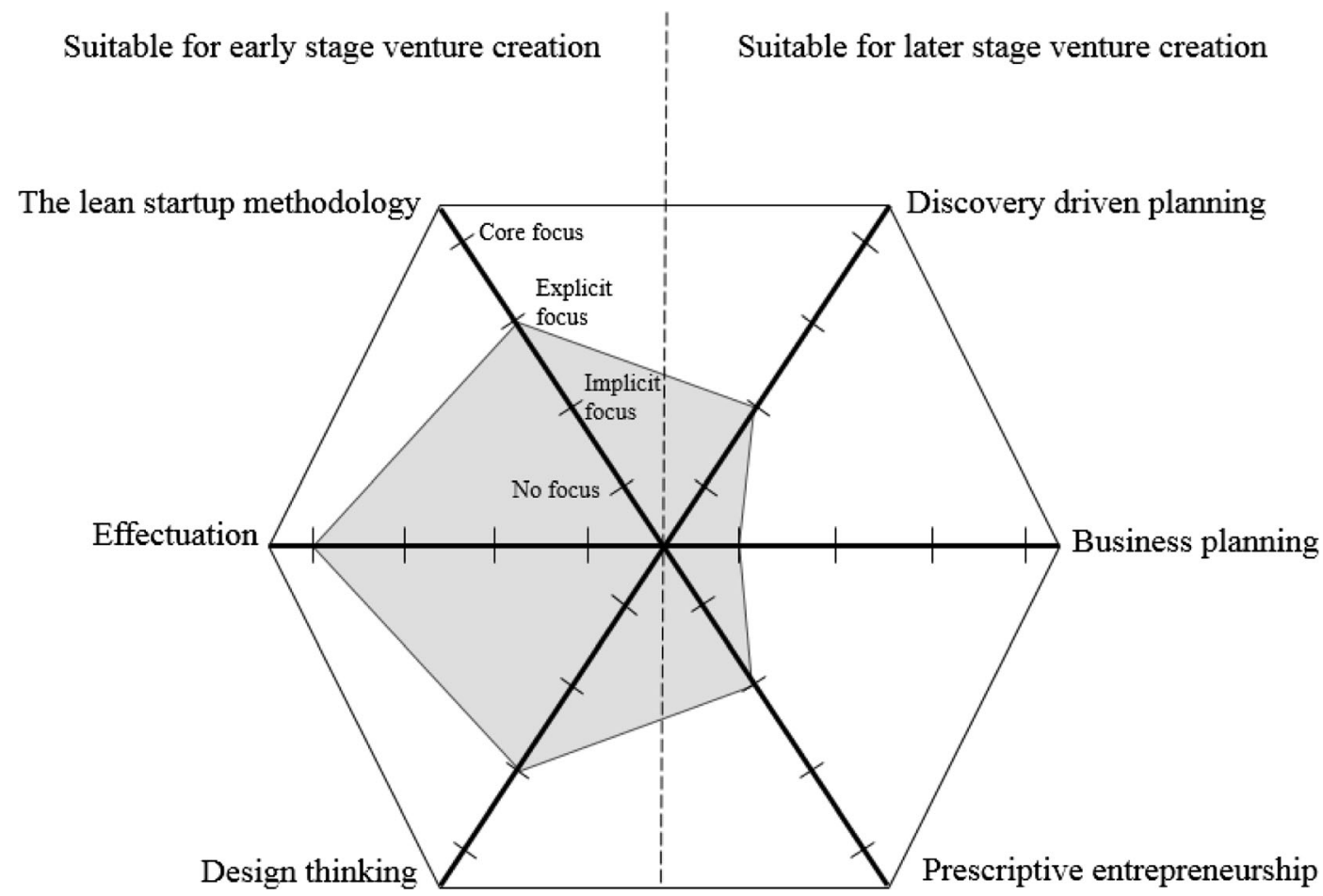

Fig. 4 Polar chart showing how emphasis on redirection power sets apart entrepreneurial methods suitable for early-stage venture creation from methods suitable for later stage venture creation

continuous learning from feedback, in an iterative and interactive manner involving close collaborators, acting to create new kinds of value for oneself and for others.

\subsection{Implications for practice}

Some key implications for practice are also evident. Entrepreneurs should reflect critically on advice given to them to decide if and when an entrepreneurial method is suitable for their purposes, taking into consideration development stage and context (Reymen et al. 2015). Ease of use does not imply future venture success. The lack of theoretical rigor among the entrepreneurial methods, especially in the areas of uncertainty management and team collaboration, suggests that entrepreneurs might need to develop their own comprehensive understanding of these two key issues. For example, the methods have a tendency to provide ready-made answers instead of inspiring entrepreneurs to undertake their own processes of discovery when facing an unknown situation. Entrepreneurs could also benefit from being aware of the shortcomings of business planning, in terms of its misalignment with many key dimensions of the entrepreneurial process. Early-stage financiers could take stock of this discrepancy and draw upon other entrepreneurial methods when assessing which ventures to fund. If scholars act upon the theoretical implications mentioned above, entrepreneurs will have access to more comprehensive and empirically studied meta-methods that place the context and development stage of the venture at the center of prescriptive efforts.

\subsection{Implications for educators and policymakers}

This study also has implications for educators and policymakers. Educators can now use the three-tiered framework and the nine conceptual dimensions to help students make sense of the existing entrepreneurial methods, illustrating their strengths, weaknesses, and complementarities. The temporal, contextual, directional, and uncertainty-related differences presented here can also be explored in more depth in academic settings as a way of teaching and communicating them more 
effectively. The rigor-relevance gap, exhibited by entrepreneurial methods as well as other submanagement theories, calls for attention from educators who rely on these methods in practically oriented courses and modules. Educators could communicate with students in a transparent manner about limitations in theoretical rigor, applicability, actionability, empirical evidence base, and contextual sensitivity. Methods that are exciting or convenient to teach, such as the lean startup methodology and business planning, are not effective in all settings. Moreover, policymakers could address these shortcomings in research, education, and entrepreneurial ecosystems by demanding more practical relevance from their research grants. In this way, policymakers could inspire researchers, educators, incubator and accelerator coaches, university officials, entrepreneurship consultants, ecosystem designers, and others to raise the bar for theoretical rigor and at the same time, for contextual relevance and applicability. These efforts would strengthen the empirical evidence base of the entrepreneurial methods that are being studied, recommended, and implemented in a multitude of settings.

\section{Conclusions}

The comparison undertaken here has positioned empirical, theoretical and prescriptive work on entrepreneurial methods as an emerging scholarly field of not only inquiry but also of design (Romme 2016). Instead of studying effectuation as a dominant logic for "the entrepreneurial method" (cf. Sarasvathy and Venkataraman 2011), scholars and practitioners could use the plural term "entrepreneurial methods" as a vehicle for coming together in co-creation efforts to bridge a rigorrelevance gap. This could be a pragmatic way to make the entrepreneurial process more explicit, graspable, teachable, and ultimately more successful. Such collaborative work will likely require a partial departure from detached observation-based research methods and instead require researchers to work closely with practitioners in prescriptive endeavors where empirical data is rigorously collected around what works, when, for whom, and in which context.

Open Access This article is distributed under the terms of the Creative Commons Attribution 4.0 International License (http:// creativecommons.org/licenses/by/4.0/), which permits unrestricted use, distribution, and reproduction in any medium, provided you give appropriate credit to the original author(s) and the source, provide a link to the Creative Commons license, and indicate if changes were made.

Publisher's note Springer Nature remains neutral with regard to jurisdictional claims in published maps and institutional affiliations.

\section{References}

Abrahamson, E. (1991). Managerial fads and fashions: the diffusion and rejection of innovations. Academy of Management Review, 16(3), 586-612.

Ackoff, R. L. (1981). Creating the corporate future: Plan or be planned for. Austin, TX: University of Texas Press.

Alvarez, S. A., \& Barney, J. B. (2007). Discovery and creation: alternative theories of entrepreneurial action. Strategic Entrepreneurship Journal, 1(1-2), 11-26.

Anthony, E. (1963). Approach, method, and technique. ELT Journal, 17(2), 63-67.

Arend, R. J., Sarooghi, H., \& Burkemper, A. (2015). Effectuation as ineffectual? Applying the $3 \mathrm{E}$ theory-assessment framework to a proposed new theory of entrepreneurship. Academy of Management Review, 40(4), 630-651.

Argyris, C. (1976). Single-loop and double-loop models in research on decision making. Administrative Science Quarterly, 21(3), 363-375.

Argyris, C., \& Schön, D. A. (1974). Theory in practice: increasing professional effectiveness. San Francisco, CA: Jossey-Bass.

Baker, T., \& Nelson, R. E. (2005). Creating something from nothing: resource construction through entrepreneurial bricolage. Administrative Science Quarterly, 50(3), 329-366.

Banks, G. C., Pollack, J. M., Bochantin, J. E., Kirkman, B. L., Whelpley, C. E., \& O’Boyle, E. H. (2016). Management's science-practice gap: a grand challenge for all stakeholders. Academy of Management Journal, 59(6), 2205-2231.

Baron, R. A. (2004). Potential benefits of the cognitive perspective: expanding entrepreneurship's array of conceptual tools. Journal of Business Venturing, 19(2), 169-172.

Bell, D. E., Raiffa, H., \& Tversky, A. (1988). Descriptive, normative, and prescriptive interactions in decision making. In D. E. Bell, H. Raiffa, \& A. Tversky (Eds.), Decision making: descriptive, normative, and prescriptive interactions (pp. 932). Cambridge, NY: Cambridge University Press.

Blank, S. G. (2007). The four steps to the epiphany: successful strategies for products that win. San Mateo, CA: Cafepress.

Blank, S. G. (2013). Why the lean startup changes everything. Harvard Business Review, 91(5), 63-72.

Blank, S. G., \& Dorf, B. (2012). The startup owner's manual: the step-by-step guide for building a great company. Pescadero, CA: K\&S Ranch Publishers, Inc..

Brinckmann, J., Grichnik, D., \& Kapsa, D. (2010). Should entrepreneurs plan or just storm the castle? A meta-analysis on contextual factors impacting the business planningperformance relationship in small firms. Journal of Business Venturing, 25(1), 24-40. 
Brown, T. (2008). Design thinking. Harvard Business Review, 86(6), 84-92.

Brown, T. (2009). Change by design. New York, NY: Harper Collins.

Bruyat, C., \& Julien, P.-A. (2001). Defining the field of research in entrepreneurship. Journal of Business Venturing, 16(2), 165180.

Bryman, A., \& Bell, E. (2007). Business research methods. Oxford: Oxford University Press Inc..

Carlgren, L., Rauth, I., \& Elmquist, M. (2016). Framing design thinking: the concept in idea and enactment. Creativity and Innovation Management, 25(1), 38-57.

Casadesus-Masanell, R., \& Ricart, J. E. (2010). From strategy to business models and onto tactics. Long Range Planning, 43(2), 195-215.

Christiansen, J. (2009). Copying Y Combinator, a framework for developing seed accelerator programmes. MBA Dissertation. Cambridge, UK: University of Cambridge.

Clarysse, B., \& Moray, N. (2004). A process study of entrepreneurial team formation: the case of a research-based spin-off. Journal of Business Venturing, 19(1), 55-79.

Cohen, W. M., \& Levinthal, D. A. (1990). Absorptive capacity: a new perspective on learning and innovation. Administrative Science Quarterly, 35, 128-152.

Cross, R., \& Sproull, L. (2004). More than an answer: information relationships for actionable knowledge. Organization Science, 15(4), 446-462.

D'Abate, C. P., Eddy, E. R., \& Tannenbaum, S. I. (2003). What's in a name? A literature-based approach to understanding mentoring, coaching, and other constructs that describe developmental interactions. Human Resource Development Review, 2(4), 360-384.

Dean, J. W., \& Bowen, D. E. (1994). Management theory and total quality: improving research and practice through theory development. Academy of Management Review, 19(3), 392418.

Delmar, F., \& Shane, S. (2003). Does business planning facilitate the development of new ventures? Strategic Management Journal, 24(12), 1165-1185.

Delmar, F., \& Shane, S. (2004). Legitimating first: Organizing activities and the survival of new ventures. Journal of Business Venturing, 19(3), 385-410.

Denyer, D., Tranfield, D., \& Van Aken, J. E. (2008). Developing design propositions through research synthesis. Organization Studies, 29(3), 393-413.

Dew, N., \& Sarasvathy, S. D. (2010). What effectuation is not: further development of an alternative to rational choice. Paper presented at the Annual Meeting of the Academy of Management, Denver, CO, 12 August 2010.

Dew, N., Read, S., Sarasvathy, S. D., \& Wiltbank, R. (2008). Outlines of a behavioral theory of the entrepreneurial firm. Journal of Economic Behavior \& Organization, 66(1), 3759.

Dew, N., Read, S., Sarasvathy, S. D., \& Wiltbank, R. (2009). Effectual versus predictive logics in entrepreneurial decision-making: differences between experts and novices. Journal of Business Venturing, 24(4), 287-309.

Dew, N., Ramesh, A., Read, S., \& Sarasvathy, S. D. (2018). Toward deliberate practice in the development of entrepreneurial expertise: The anatomy of the effectual ask. In K. A. Ericsson, N. Charness, P. J. Feltovich, \& R. R. Hoffman
(Eds.), The Cambridge handbook of expertise and expert performance (2nd ed., pp. 389-412). Cambridge: Cambridge University Press.

Dimov, D. (2016). Toward a design science of entrepreneurship. In J. Katz \& A. C. Corbett (Eds.), Models of start-up thinking and action: theoretical, empirical and pedagogical approaches (pp. 1-31). Bingley: Emerald Group Publishing.

Dorst, K. (2011). The core of 'design thinking' and its application. Design Studies, 32(6), 521-532.

Draman, R. H. (1995). A new approach to the development of business plans: a cross functional model using the theory of constraints philosophies. Doctoral dissertation. Athens, GA: University of Georgia.

Dunne, D., \& Martin, R. (2006). Design thinking and how it will change management education: an interview and discussion. Academy of Management Learning \& Education, 5(4), 512523.

Dybå, T., \& Dingsøyr, T. (2008). Empirical studies of agile software development: a systematic review. Information and Software Technology, 50(9), 833-859.

Eisenmann, T., Ries, E., \& Dillard, S. (2012). Hypothesis-driven entrepreneurship: the lean startup. Harvard Business School Entrepreneurial Management Case, No. 812-095, Boston, MA.

Fiet, J. O. (2002). The systematic search for entrepreneurial discoveries. Westport, CT: Quorum Books.

Fiet, J. O. (2007). A prescriptive analysis of search and discovery. Journal of Management Studies, 44(4), 592-611.

Fiet, J. O. (2008). Prescriptive entrepreneurship. Cheltenham: Edward Elgar Publishing.

Fiet, J. O., \& Patel, P. C. (2008). Entrepreneurial discovery as constrained, systematic search. Small Business Economics, 30(3), 215-229.

Fiet, J. O., Norton, W. I., \& Clouse, V. G. (2013). Search and discovery by repeatedly successful entrepreneurs. International Small Business Journal, 31(8), 890-913.

Fishbein, M., \& Ajzen, I. (2010). Predicting and changing behavior: the reasoned action approach. New York, NY: Psychology Press.

Fisher, G. (2012). Effectuation, causation, and bricolage: a behavioral comparison of emerging theories in entrepreneurship research. Entrepreneurship Theory and Practice, 36(5), 1019-1051.

Foss, K., Foss, N. J., \& Klein, P. G. (2007). Original and derived judgment: an entrepreneurial theory of economic organization. Organization Studies, 28(12), 1893-1912.

Frank, H., \& Landström, H. (2016). What makes entrepreneurship research interesting? Reflections on strategies to overcome the rigor-relevance gap. Entrepreneurship and Regional Development, 28(1-2), 51-75.

Furr, N., \& Ahlstrom, P. (2011). Nail it then scale it: the entrepreneur's guide to creating and managing breakthrough innovation. Lexington, KY: NISI Institute.

Garud, R., \& Karnøe, P. (2003). Bricolage versus breakthrough: distributed and embedded agency in technology entrepreneurship. Research Policy, 32(2), 277-300.

Gauthier, J. F., Penzel, M., \& Marmer, M. (2017). Global startup ecosystem report 2017 . https://startupgenome. com/report2017/. Accessed February 7, 2018.

Gomory, R. E. (1995). The known, the unknown and the unknowable. Scientific American, 272(6), 120-120. 
Hanks, S. H., Watson, C. J., Jansen, E., \& Chandler, G. N. (1994). Tightening the life-cycle construct: a taxonomic study of growth stage configurations in high-technology organizations. Entrepreneurship Theory and Practice, 18(2), 5-29.

Harmeling, S. S., \& Sarasvathy, S. D. (2013). When contingency is a resource: educating entrepreneurs in the Balkans, the Bronx, and beyond. Entrepreneurship Theory and Practice, 37(4), 713-744.

Harper, D. A. (2008). Towards a theory of entrepreneurial teams. Journal of Business Venturing, 23(6), 613-626.

Hart, S. L., \& Sharma, S. (2004). Engaging fringe stakeholders for competitive imagination. The Academy of Management Executive, 18(1), 7-18.

Heitmann, J. (2014). The lean startup: a pragmatic view on its flaws and pitfalls. Master's thesis, University of Twente, Twente, The Netherlands.

Hong, J., Song, T. H., \& Yoo, S. (2013). Paths to success: how do market orientation and entrepreneurship orientation produce new product success? Journal of Product Innovation Management, 30(1), 44-55.

Johansson-Sköldberg, U., Woodilla, J., \& Çetinkaya, M. (2013). Design thinking: past, present and possible futures. Creativity and Innovation Management, 22(2), 121-146.

Jones, C., \& Penaluna, A. (2013). Moving beyond the business plan in enterprise education. Education + Training, 55(8/9), 804-814.

Karlsson, T., \& Honig, B. (2009). Judging a business by its cover: an institutional perspective on new ventures and the business plan. Journal of Business Venturing, 24(1), 27-45.

Khanna, R., Guler, I., \& Nerkar, A. (2016). Fail often, fail big, and fail fast? Learning from small failures and R\&D performance in the pharmaceutical industry. Academy of Management Journal, 59(2), 436-459.

Kirzner, I. M. (1997). Entrepreneurial discovery and the competitive market process: an Austrian approach. Journal of Economic Literature, 35(1), 60-85.

Klein, L. (2013). UX for lean startups: faster, smarter user experience research and design. Sebastopol, CA: O'Reilly Media, Inc..

Klotz, A. C., Hmieleski, K. M., Bradley, B. H., \& Busenitz, L. W. (2014). New venture teams: A review of the literature and roadmap for future research. Journal of Management, 40(1), 226-255.

Knight, F. H. (1921). Risk, uncertainty and profit. New York, NY: Hart, Schaffner and Marx.

Kolb, D. A. (1984). Experiential learning: experience as the source of learning and development. Englewood Cliffs, NJ: Prentice Hall.

Korsgaard, S., \& Anderson, A. R. (2011). Enacting entrepreneurship as social value creation. International Small Business Journal, 29(2), 135-151.

Kotha, R., \& George, G. (2012). Friends, family, or fools: entrepreneur experience and its implications for equity distribution and resource mobilization. Journal of Business Venturing, 27(5), 525-543.

Lackéus, M. (2016). Value creation as educational practice- towards a new educational philosophy grounded in entrepreneurship? Doctoral dissertation, Chalmers University of Technology, Gothenburg, Sweden.

Landa, L. N. (1999). Landamatics instructional design theory and methodology for teaching general methods of thinking. In C.
M. Reigeluth (Ed.), Instructional-design theories and models: a new paradigm of instructional theory (Vol. 2, pp. 341-369). Hillsdale, NJ: Lawrence Erlbaum Associates.

Leavy, B. (2010). Design thinking - a new mental model of value innovation. Strategy \& Leadership, 38(3), 5-14.

Lechler, T. (2001). Social interaction: a determinant of entrepreneurial team venture success. Small Business Economics, 16(4), 263-278.

Levie, J., \& Lichtenstein, B. B. (2010). A terminal assessment of stages theory: introducing a dynamic states approach to entrepreneurship. Entrepreneurship Theory and Practice, 34(2), 317-350.

Liedtka, J. (2015). Perspective: linking design thinking with innovation outcomes through cognitive bias reduction. Journal of Product Innovation Management, 32(6), 925-938.

Liedtka, J., \& Ogilvie, T. (2011). Designing for growth: a design thinking toolkit for managers. New York: Columbia University Press.

Lundvall, B.-Å. (1992). User-producer relationships, national systems of innovation and internationalization. In B.- $\AA$. Lundvall (Ed.), National Systems of innovation: towards a theory of innovation and interactive learning (pp. 45-67). London: Pinter Publishers.

Mansoori, Y. (2015). Entrepreneurial methods. Licentiate dissertation. Gothenburg, Sweden: Chalmers University of Technology.

Mansoori, Y. (2017). Entrepreneurial methods as vehicles of entrepreneurial action. Doctoral dissertation. Gothenburg, Sweden: Chalmers University of Technology.

March, S. T., \& Smith, G. F. (1995). Design and natural science research on information technology. Decision Support Systems, 15(4), 251-266.

Marmer, M., Herrmann, B.L., Dogrultan, E., Berman, R., Eesley, C., \& Blank, S. (2011). Startup genome report extra: premature scaling. http://innovationfootprints.com/wpcontent/uploads/2015/07/startup-genome-report-extra-onpremature-scaling.pdf. Accessed February 8, 2018.

Martin, R. (2009). The design of business. Boston, MA: Harvard Business School Publishing.

Maurya, A. (2012). Running lean: iterate from plan A to a plan that works. Sebastopol, CA: O'Reilly Media, Inc..

McGrath, R. G., \& MacMillan, I. C. (1995). Discovery driven planning. Harvard Business Review, 1995(July-August), 4454.

McGrath, R. G., \& MacMillan, I. C. (2000). The entrepreneurial mindset: strategies for continuously creating opportunity in an age of uncertainty. Boston, MA: Harvard Business School Press.

McKelvie, A., Haynie, J. M., \& Gustavsson, V. (2011). Unpacking the uncertainty construct: implications for entrepreneurial action. Journal of Business Venturing, 26(3), 273-292.

McMullen, J. S., \& Shepherd, D. A. (2006). Entrepreneurial action and the role of uncertainty in the theory of the entrepreneur. Academy of Management Review, 31(1), 132-152.

Minniti, M., \& Bygrave, W. (2001). A dynamic model of entrepreneurial learning. Entrepreneurship Theory and Practice, 25(3), 5-16.

Murray, F., \& Tripsas, M. (2004). The exploratory processes of entrepreneurial firms: the role of purposeful experimentation. In J. A. C. Baum \& A. M. McGahan (Eds.), Business strategy over the industry lifecycle (advances in strategic 
management) (Vol. 2, pp. 45-75). Bingley, West Yorkshire: Emerald Group Publishing Limited.

Neck, H. M., \& Greene, P. G. (2011). Entrepreneurship education: known worlds and new frontiers. Journal of Small Business Management, 49(1), 55-70.

Neck, H. M., Greene, P. G., \& Brush, C. G. (2014). Teaching entrepreneurship: a practice-based approach. Cheltenham: Edward Elgar Publishing.

Osterwalder, A., \& Pigneur, Y. (2010). Business model generation: a handbook for visionaries, game changers, and challengers. Hoboken, NJ: John Wiley \& Sons.

Ozdemir, S. Z., Moran, P., Zhong, X., \& Bliemel, M. J. (2016). Reaching and acquiring valuable resources: the entrepreneur's use of brokerage, cohesion, and embeddedness. Entrepreneurship Theory and Practice, 40(1), 49-79.

Parsons, T., Shils, E. A., \& Smelser, N. J. (1965). Toward a general theory of action: theoretical foundations for the social sciences. New Brunswick, NJ: Transaction Publishers.

Pfeffer, J., \& Sutton, R. I. (2006). Evidence-based management. Harvard Business Review, 84(1), 62.

Porter, M. E. (1980). Competitive strategy: techniques for analyzing industries and competitors. New York, NY: The Free Press.

Rauth, I. (2015). Understanding management ideas: the development of interpretability. Doctoral dissertation, Chalmers University of Technology, Gothenburg, Sweden.

Read, S., Dew, N., Sarasvathy, S. D., Song, M., \& Wiltbank, R. (2009). Marketing under uncertainty: The logic of an effectual approach. Journal of marketing, 73(3), 1-18.

Read, S., Sarasvathy, S. D., Dew, N., \& Wiltbank, R. (2016). Effectual entrepreneurship. New York, NY: Routledge.

Reymen, I. M., Andries, P., Berends, H., Mauer, R., Stephan, U., \& Burg, E. (2015). Understanding dynamics of strategic decision making in venture creation: a process study of effectuation and causation. Strategic Entrepreneurship Journal, 9(4), 351-379.

Richards, J. C., \& Rodgers, T. S. (2014). Approaches and methods in language teaching. Cambridge: Cambridge University Press.

Ries, E. (2011). The lean startup: how today's entrepreneurs use continuous innovation to create radically successful businesses. New York, NY: Random House Digital.

Rogers, E. M. (1983). Diffusion of innovations (Third ed.). New York, NY: The Free Press.

Romme, A. G. L. (2003). Making a difference: organization as design. Organization Science, 14(5), 558-573.

Romme, A. G. L. (2016). The quest for professionalism: the case of management and entrepreneurship. Oxford: Oxford University Press.

Romme, A. G. L., \& Endenburg, G. (2006). Construction principles and design rules in the case of circular design. Organization Science, 17(2), 287-297.

Rynes, S. L., Bartunek, J. M., \& Daft, R. L. (2001). Across the great divide: knowledge creation and transfer between practitioners and academics. Academy of Management Journal, 44(2), 340-355.

Sarasvathy, S. D. (2001). Causation and effectuation: toward a theoretical shift from economic inevitability to entrepreneurial contingency. Academy of Management Review, 26(2), 243-263.
Sarasvathy, S. D. (2003). Entrepreneurship as a science of the artificial. Journal of Economic Psychology, 24(2), 203-220.

Sarasvathy, S. D. (2009). Effectuation: elements of entrepreneurial expertise. Cheltenham: Edward Elgar Publishing.

Sarasvathy, S. D., \& Dew, N. (2005a). Entrepreneurial logics for a technology of foolishness. Scandinavian Journal of Management, 21(4), 385-406.

Sarasvathy, S. D., \& Dew, N. (2005b). New market creation through transformation. Journal of Evolutionary Economics, 15(5), 533-565.

Sarasvathy, S. D., \& Venkataraman, S. (2011). Entrepreneurship as method: open questions for an entrepreneurial future. Entrepreneurship Theory and Practice, 35(1), 113-135. Sarasvathy, S. D., Dew, N., Velamuri, S. R., \& Venkataraman, S. (2003). Three views of entrepreneurial opportunity. In Z. Acs \& D. B. Audretsch (Eds.), Handbook of entrepreneurial research (pp. 141-160). Dordrecht, the Netherlands: Kluwer Academic Publishers.

Sarasvathy, S. D., Dew, N., Read, S., \& Wiltbank, R. (2008). Designing organizations that design environments: lessons from entrepreneurial expertise. Organization Studies, 29(3), 331-350.

Sonalkar, N., Mabogunje, A., \& Leifer, L. (2016). Developing a design thinking curriculum for venture creation in resourceconstrained environment. International Journal of Engineering Education, 32(3), 1372-1384.

Steinhoff, H. W. (1971). Dynamic business planning under conditions of uncertainty. Doctoral dissertation. Faculty of the Graduate School of Business Administration, University of Southern California, CA.

Sull, D. (2004). Disciplined entrepreneurship. Sloan Management Review, 46(1), 71-77.

Tang, J., Kacmar, K. M. M., \& Busenitz, L. (2012). Entrepreneurial alertness in the pursuit of new opportunities. Journal of Business Venturing, 27(1), 77-94.

Tetlock, P. E., \& Gardner, D. (2016). Superforecasting: the art and science of prediction. New York, NY: Random House.

Thomke, S. H. (1998). Managing experimentation in the design of new products. Management Science, 44(6), 743-762.

Thomke, S. H. (2003). Experimentation matters: unlocking the potential of new technologies for innovation. Boston, MA: Harvard Business Press.

Tietz, R. (1992). Semi-normative theories based on bounded rationality. Journal of Economic Psychology, 13(2), 297-314.

Tsang, E. W. (1997). Organizational learning and the learning organization: a dichotomy between descriptive and prescriptive research. Human Relations, 50(1), 73-89.

Tunisini, A., \& Zanfei, A. (1998). Exploiting and creating knowledge through customer-supplier relationships: lessons from a case study. R\&D Management, 28(2), 111-118.

Upton, N., Teal, E. J., \& Felan, J. T. (2001). Strategic and business planning practices of fast growth family firms. Journal of Small Business Management, 39(1), 60-72.

Utterback, J. M., \& Abernathy, W. J. (1975). A dynamic model of process and product innovation. Omega, 3(6), 639-656.

Van de Ven, A. H., \& Johnson, P. E. (2006). Knowledge for theory and practice. Academy of Management Review, 31(4), 802821.

Vincenti, W. G. (1990). What engineers know and how they know it: analytical studies from aeronautical history. Baltimore, MD: The Johns Hopkins University Press. 
Weick, K. E. (2001). Gapping the relevance bridge: fashions meet fundamentals in management research. British Journal of Management, 12(S1), S71-S75.

Wiltbank, R., Dew, N., Read, S., \& Sarasvathy, S. D. (2006). What to do next? The case for non-predictive strategy. Strategic Management Journal, 27(10), 981-998.

Wiltbank, R., Read, S., Dew, N., \& Sarasvathy, S. D. (2009). Prediction and control under uncertainty: outcomes in angel investing. Journal of Business Venturing, 24(2), 116-133.
Wiltbank, R.E. \& Sarasvathy, S.D. (2010). What effectuation is not: Further development of an alternative to rational choice. Academy of Management Conference, Montreal Canada.

Wolf, J., \& Rosenberg, T. (2012). How individual scholars can reduce the rigor-relevance gap in management research. Business Research, 5(2), 178-196.

Wood, J. (2000). The culture of academic rigor: does design research really need it? The Design Journal, 3(1), 44-57. 